\title{
Die Entstehung der pfälzisch-österreichischen Convention vom 3. Januar 1778.
}

\author{
Von
}

\section{Adolf Unzer.}

Das Herzogtum Bayern, das Flussgebiet des Inns und der Isar bis zum Lech hin zu erwerben war lange das Ziel österreichischer Staatskunst.

Um die Mitte des achtzehnten Jahrhunderts eröffnete sich dem Wiener Hof eine neue Aussicht dies Ziel zu erreichen. Der Kurfürst von Bayern Maximilian Joseph war kinderlos; auch sein Oheim, Herzog Clemens $(\dagger 1770)$ hatte keine erbberechtigten Nachkommen. Mit ihm erlosch die bayerische oder wilhelminische Linie des Hauses Wittelsbach; als der natürliche Erbe galt Karl Theodor, Herzog von Sulzbach, seit 1742 Kurfürst von der Pfalz und Chef der pfälzischen oder rudolphinischen Linie.

Frühzeitig hatte der österreichische Staatskanzler Fürst Kaunitz seinen Blick der bayerischen Successionsfrage zugewandt; im zehnten Band der Geschichte Maria Theresias hat Arneth, die Mitteilungen Beers in Sybels historischer Zeitschrift 1) ergänzend, die frühesten Phasen dieser wichtigen Staatsaction mitgeteilt.

Im Dezember 1772 fanden in Wien geheime Beratungen über die bei Maximilian Josephs Tod zu ergreifenden Massregeln statt, an denen der österreichische Directorialgesandte bei dem Reichstag zu Regensburg, Freiherr von Borié, der Reichsvizekanzler Fürst Colloredo, der Geheime Referendarius in der Reichskanzlei Freiherr von Leykam und als Vertreter der Staatskanzlei der Freiherr von Binder theilnahmen; der Kaiser selbst hatte auf eine Anregung Boriés hin die Beratungen an-

1) Bd. $35 \mathrm{~S} .88 \mathrm{f}$. 
geordnet. Es wurde beschlossen, dass bei dem Ableben des bayerischen Kurfürsten sofort die Besitzergreifung von Ober- und Niederbayern, sowie der Landgrafschaft Leuchtenberg als erledigter Reichslehen im Namen von Kaiser und Reich erfolgen solle; Borié am Reichstag, Graf Hartig in München erhielten die nötigen Vollmachten und Anweisungen.

Nur ungern hatte Kaunitz diesen Beschlüssen von unberechenbarer Tragweite zugestimmt; weit lieber wäre es ihm gewesen, wenn man die Angelegenheit noch in dem bisherigen Ruhezustand belassen hätte. Es war nicht anzunehmen, dass von anderer Seite jetzt schon diese offenbar noch lange nicht spruchreife Frage ernsthaft angeregt werde; der König von Preussen hatte sie zwar im September 1772 dem auf Urlaub gehenden kaiserlichen Gesandten gegenüber berührt, als aber van Swieten im Februar 1773 mit eingehenden Weisungen versehen nach Berlin zurückkehrte, schien Friedrich sie bald wieder aus den Augen zu verlieren; näher liegende Verhältnisse nahmen seine Aufmerksamkeit in Anspruch. Die von Kaunitz dringend anempfohlene Geheimhaltung und Vorsicht bei Ausfährung der gefassten Conferenzbeschlüsse wurde indes gewissenhaft beobachtet. Der Wiener Hof vermied es sorgfältig, die bayerische Firbfolge zu erwähnen; es kan ihm besonders darauf an, den Verdacht zu beseitigen, als ob die von. preussischer Seite ihm zugeschriebene Vergrösserungsbegierde wirklich vorhanden sei.

Weniger vorsichtig in der Geltendmachung von Ansprüchen auf Teile der einstigen Verlassenschaft Maximilian Josephs war Kursachsen. Die verwitwete Kurfürstin Maria Antonia von Sachsen, die Mutter des seit Dezember 1763 regierenden Kurfürsten Friedrich August III, war eine Schwester Maximilian Josephs; sie und die zweite Schwester, die Markgräfin von Baden, konnten berechtigte Ansprüche auf das bayerische Allodium erheben. Schon trühzeitig wurde zwischen Dresden und Mannheim darüber verhandelt; im November 1774 überreichte der sächsische Gesandte an Hofe Karl Theodors, Graf Riaucour, eine Denkschrift; doch, wie es scheint, erst seit Anfang 1776 wurde diese Angelegenheit etwas lebhafter betrieben, ohne dass sie indes auch nur einen Schritt vorwärts kam, da man in Mannheim hoffte, durch ein Debereinkommen mit Oesterreich die sächsischen Ansprüche gänzlich beseitigen oder doch stark einschränken zu könnnen. Nur insofern trat eine Aenderung ein, als die Kurfürstin-Mutter am 1. Mai 1776 in Zweibrücken eine Cessionsacte ${ }^{1}$ ) unterzeichnete, worin sie ihre Ansprïche auf die bayerische Allodialerbschaft an ibren Sohn, den regierenden Kurfürsten

') Datirt rom 20. April. 
abtrat. Die von den pfälzischen Staatsmännern wiederholt als Vorwand zur Verzögerung der Unterhandlungen benützte angebliche Meinungsverschiedenheit zwischen Mutter und Sohn über die Lösung der Allodialfrage konnte nun nicht mehr ins Treffen geführt werden. Als unmittelbar danach, an 7. Mai 1776, die Markgräfin von Baden in München starb, war Maria Antonia bezw. ihr Sohn der einzige Allodialerbe. - Der Grund, weshalb Sachsen die Verhandlungen lebhafter in Angriff nahm, erhellt aus der Correspondenz des Grafen Riaucour mit dem Minister Grafen Sacken in Dresden. Man hatte vernommen, dass von pfälzischer Seite eine Vereinbarung mit dem Wiener Hof gesucht werde, dass der pfälzische Minister der Auswärtigen Angelegenheiten, der hochbetagte Freiherr von Beckers die Hauptrolle dabei spiele; es hiess sogar, er habe es auf sich genommen, sich öffentlich desarouiren zu lassen, wenn die Verhandlungen bekannt würden. Doch erfuhr man wieder nicht lange danach durch einen Bericht des kurpfälzisehen Gesandten in Wien, Freiherrn von Ritter, vom 26. September 1775 , den Riaucour sich zu verschaffen wusste, dass wenigstens zu jener Zeit die beiden Höfe von einer Verständigung sehr weit entfernt gewesen waren; ja, Ritter hatte sogar die Besorgnis ausgesprochen, dass Oesterreich mit anderen Staaten entweder bereits einig sei oder nahe vor einer Verständigung stehe taber die Teilung der bayerischen Erbschaft. - Ritter hat hier offenbar eine Gefabr zu sehen geglaubt, die in Wirklichkeit nicht vorhanden war; wenn er aber berichtet: - Kaunitz und Colloredo erschöpfen die ohndurchdringlichste politique; Wörter und Sylben werden gleichsam abgewogen und über die ohnzähligemal angegebenen und stathaft bestrittene Hindernisse immer neue Verzögerungen erfunden, " - so entspricht dies Verhalten vollkommen dem System, das Kaunitz anempfohlen hatte, nämlich grösste Zurückhaltung zu bewahren.

Da ich im Bayerischen Geheimen Staats-Archiv zu München Berichte Ritters aus der Zeit vor Dezember 1777 nicht gefunden habe, möge es mir gestattet sein, an dieser Stelle einige Angaben über den Inhalt der anderen von Riaucour erlangten und nach Dresden gesandten Depeschen Ritters zu machen.

Mit unsäglicher Mühe war es danach Anfang October 1775 dem kurpfälizischen Gesandten gelungen, durch Vermittlung des Freiherrn von Hochstetten, eines Beamten der Geheimen Staatskanzlei, eine lange Liste zu erhalten mit einem Verzeichnis aller derjenigen Ortschaften, die in Folge eines angeblich zwischen Oesterreich und Preussen geschlossenen Vertrags an den Wiener Hof fallen sollten. Nach dieser Aufzählung wäre allerdings von der Oberpfalz und Niederbayem nur 
wenig, von Oberbayern nicht viel der österreichischen Begehrlichkeit vorenthalten geblieben. Es scheint indes, dass Ritter mit dieser Liste von dem Sekretär des Fürsten Kaunitz, der sie ihm überbrachte, getäuscht worden ist; vielleicht enthielt sie nur das Verzeichnis aller derjenigen Ortschaften, auf die der Wiener Hof ans irgend einem Grunde einen Anspruch erheben zu können glaubte. Sacken wenigstens meinte, als ihm Riaucour die Liste einschickte, sie sähe aus wie der Index eines Werkes, in dem die österreichischen und die kaiserlichen Ansprüche erst begründet werden sollten; vielleicht gehöre sie zu der vom Kaiser angeordneten Ausarbeitung einer umfassenden Denkschrift über die aus der bayrischen Hinterlassenschaft zu erwerbenden Gebiete.

Von einer kritischen Beurteilung des ihm zugestellten Verzeichnisses war aber Ritter weit entfernt. Er klagt entsetzt über die wienerische Verstellungskunst, über die Ungeheuerlichkeit der österreichischen Entwürfe, die über die schlimmsten bisherigen Vermutungen noch weit hinausgingen. Alle seither gepflogenen Unterhandlungen seien also nichts als Blendwerk gewesen; aber auch jeden weiteren Sohritt sieht er als nutzlos und verloren an, solange Kaunitz und Colloredo am Ruder sind und das Uebergewicht über die Gegenpartei behaupten; nur von der Zukunft oder dem Spiele des Zufalls lasse sich eine Aenderung der Sachlage erhoffen. - Gerade diese Stimmung aber wird es wohl gewesen sein, die Kaunitz mit der Mitteilung jener Liste an Ritter herbeizuführen beabsichtigte: er wollte Ruhe haben vor den Anwürfen der ruhelosen Politik des Freiherrn von Beckers. Ein weiterer, als geheim bezeichneter Bericht Ritters an Beckers vom 27. Februar 1776 lässt vermuten, dass der Minister in Mannheim die übermittelten Allarmnachrichten mit kritischerem Auge betrachtete als der Gesandte. dass er bessere, zuverlässigere Mitteilungen verlangte; aber vergeblich setzte Ritter alle seine Vertrauensmänner in Bewegung: nichts erfuhr er als "zweideutige, elende und längst bekannte Sachen". Dagegen versicherte ihm Hochstetten, auf dessen Angaben er sich verlassen zu dürfen glaubte, von Neuem, die ganze bayerische Erbschaft sei schon im vorigen Jahre zwischen dem kaiserlichen und dem preussischen Hof durch einen Partagetractat völlig geordnet worden.

Wie schon angedeutet, glaubte Riaucour das, was er von einem österreichisch-preussischen Einverständnis in der bayerischen Angelegenheit vernahm; er behauptete sogar, dass dabei Sachsen die Grafschaft Cham und eine hübsche Geldsumme zugewiesen sei. Aber gleichzeitig kam ihm doch auch wieder mancherlei zu Ohren, was damit nicht übereinstimmte: er hörte, Beckers habe dem Wiener Hof den jenseits des 
Inns zwischen dem Erzherzogtum 0esterreich und dem Erzbistum Salzburg gelegenen Teil von Bayern angeboten und erwarte die Antwort darauf. Dem König von Preussen sollten Jülich-Berg zufallen gegen Abtretung der Markgrafschaften Ansbach und Baireuth an Kurbayern. Eine gewisse Bestätigung dieser ihm von dem Obersthofmeister der Kurfürstin von der Pfalz, dem Fürsten Galean gemachten Mitteilungen sah Riaucour in den häufigen Besprechungen des zu vorübergehendem Aufenthalt in Mannheim eingetroffenen kaiserlichen Gesandten, des Landkomthurs Freiherrn von Lehrbach, mit dem Kurfürsten und Beckers. Bald hiess es, der Kaiserhof habe dem pfälzischen seine Unterstïtzung in der bayerischen Suecessionsfrage in sichere Aussicht gestellt und verlange nur die Theilnahme des Kurfürsten Maximilian Joseph.; zugleich aber tauchte das Gerücht auf, dass Frankreich Ansprüche an die bajerische Hinterlassenschaft zu erheben gedenke. Der französische Gesandte in Mannheim, Odunne stellte Letzteres bestimmt in Abrede, deutete aber Riaucour an, dass sein Hof zwar die Beseitigung der obwaltenden Differenzen sehnlich wünsche, um dadurch einem sonst unvermeidlichen Kriege vorzubeugen, dass er indes auch die Ausführung allzuweit gehender Pläne des Wiener Hofes verhindern werde. Es wurde ferner erzählt, Beckers habe den Herzog Karl von Zweibrücken als den präsumtiven Nachfolger Karl Theodors zu gewinnen gesucht für das Zusammengehen mit Oesterreich durch das Versprechen des goldenen Vliesses sowie eines hohen Ranges in der k. k. Armee, der Herzog habe aber kühl ablehnend geantwortet.

Beckers, dem das Bekanntwerden der Unterhandlungen überaus unangenehm war, suchte sie vergebens als einen grossen Betrug darzustellen, den seine Gegner ins Werk gesetzt hätten. Auch Karl Theodor leugnete, als die Kurfürstin-Witwe von Sachsen bei einem kurzen Aufenthalt in Mannheim (11. bis 13. April 1776) ihn über die angebliche geheime Unterhandlung in der bayerischen Erbfolgesache befragte, diese rundweg $a b$.

Es ist mit dem mir vorliegenden Aktenmaterial nicht möglich festzustellen, was den Anlass gegeben hat, dass Anfang Mai 1776 von pfälzischer Seite die Regelung der Jülich-Bergischen Erbfolge-Garantie gleichzeitig mit einer Verständigung über die künftige bayerische Succession angeregt wurde. Auf diese Anregung hin beantragte der Staatskanzler Fürst Kaunitz in einem Vortrag vor der Kaiserin-Königin am 9. Mai 1776, dass man angesichts der Bewegungen anderer Höfe und besonders des kursächsischen Hofes nicht länger unthätig bleibe; doch empfahl er zuerst an die Jülich-Berg'sche Angelegenheit heran- 
zutreten und dabei unter der Hand zu erkunden, wie Kurpfalz über die bayerische Erbfolge denke.

Denn mindestens ebenso sehr wie die vielleicht noch ferner $\mathrm{Zu}-$ kunft vorbehaltene bayerische Frage beschäftigte die pfälzischen Staatsmänner die Sicherung der Herzogthümer Jülich und Berg für das Haus Sulzbach.

In dem Allianzvertrag zwischen Preussen und Frankreich vom 5. Juni 174l hatte König Friedrich sich verpflichtet für sich und seine Nachfolger in aller Form seinen Ansprüchen auf die Erbfolge in den Herzogtümern Jülich und Berg zu entsagen zu Gunsten des Hauses Sulzbach; dagegen hatte ihm Frankreich den Besitz Niederschlesiens mit Breslau garantirt. Der Vertrag mit Kurpfalz, in dem jener Verzicht thatsächlich erfolgte, wurde am 24. Dezember 1741 abgeschlossen, im Januar 1742 ratifizirt; Kurpfalz übernahm darin ebenfalls die Garantie für Niederschlesien. Am 31. Dezember $1742 \mathrm{kam}$ die Sulzbach'sche Linie nach Karl Philipps Tod und dem Erlöschen der Neuburger Linie mit Karl Theodor in den Besitz der Kur und der Pfalz am Rhein; auch die Gemahlin, die Karl Theodor sich wählte, war eine sulzbach'sche Prinzessin. Nun nahm aber Kurpfalz im siebenjährigen Krieg gegen Preussen Partei, freilich erst nachdem von Seiten des Wiener Hofs ihm die Erbfolge in Jülich-Berg gewährleistet worden war und Frankreich die Verpflichtung übernommen hatte, im künftigen Friedensschluss Preussen zur Erneuerung des Verzichts zu veranlassen. In der That bestimmte denn auch Artikel 18 des Hubertsburger Friedensvertrags: Der König von Preussen wird die 1741 mit dem Kurfürsten von der Pfalz über die Nachfolge in Jülich-Berg geschlossene Convention erneuern unter denselben Bedingungen, unter denen sie abgeschlossen worden ist " Von preussischer Seite war bisher aber noch kein Schritt zur Erfüllung dieses Versprechens gethan worden; und auch Karl Theodor wagte nicht, nachdem im Herbst 1763 Beckers als pfälzischer Gesandter in Berlin vergeblich versucht hatte mit Ungehung Frankreichs die Erneuerung des Verzichts zu erhalten, abermals bei Preussen die Frage anzuregen, da er durch die dagegen zu gewährende Garantie Niederschlesiens in Wien Anstoss zu erregen fürchtete; noch weniger wollte er um die französische Befürwortung seines Wunsches bitten, die Friedrich zur Bedingung gemacht hatte.

Diese Angelegenheit also gedachte Kaunitz in den Vordergrund zu stellen; es entsprach das seinem Grundsatz, die bayerische Frage möglichst lang in undurchdringliches Geheimnis gehüllt zu lassen. Da aber doch allerlei in die Oeffentlichkeit gedrungen war von dem An- 
suchen des pfälzisehen Hofes in Wien, machte Lehrbach dem Grafen Riaucour Anfang Juni 1776 Mitteilung davon; er erzählte auch, dass Graf Colloredo auf der Durchreise in Mannheim sich bereit erklärt habe, seinen Vater, den Reichsvizekanzler für die pfälzischen Wünsche günstig zu stimmen; dass Graf Pappenheim sich schon grosse Hoffnung gemacht habe, mit den Verhandlungen in Wien betraut zu werden; die Aussichten zum Ziel zu kommen seien nicht schlecht gewesen, aber das Geheimnis sei nicht gewahrt wordeu, die Grafen Sıckingen, der eine pfälzischer Gesandter in Paris, z. Z. auf Urlaub in Mannheim, der andere leitender Minister in Mainz hätten eigene Politik getrieben und hinter Lehrbachs Rücken Vorschläge nach Wien geschickt; der Kurfürst von Mainz habe sich eingemischt und beschwert, dass man ihm von den ersten Eröffnungen keine Kenntnis gegeben habe; das Ergebnis von diesem Allen sei dann aber gewesen, dass man in Wien anderer Meinung wurde; jetzt würden schwerlich der Kaiser und die Kaiserin-Königin sich auf Unterhandlungen über die bayerische Erbfolge einlassen 1).

Diese Fröffnung hatte die gewünschte Wirkung: Riaucour glaubte, dass die Verhandlungen in Wien wirklich abgebrochen seien, aber er war überzeugt, dass Beckers bei nächster Gelegenheit eine neue Anknüpfung suchen werde. Gegen Ende Juni teilte ihm Odunne mit, Beckers beabsichtige sich im Lauf des Juli nach Wien zu begeben; die Unterbringung seines Sohnes im Theresianum und seiner Tochter in einem Kloster gebe den äusseren Anlass zur Reise, der Hauptzweck aber sei zweifellos die Stimmung am Kaiserhof in Sachen der bayerischen Erbfolge zu erkunden ${ }^{2}$ ). Vierzehn Tage später wusste man freilich, dass Beckers Reise doch nicht stattfinden werde; ihr Unterbleiben in Verbindung mit einem ungewohnten Eifer des pfälzischen Ministeriums wegen Eröffnung der Unterhandlung mit Kursachsen schien die Mittcilungen Lehrbachs zu bestätigen. Man erfuhr, dass der Kurfürst selber Mitte Juli sich dem Marquis d'Antici gegenüber geäussert habe, der Faden der Unterhandlung mit Wien sei gänzlich abgerissen; und Lehrbach antwortetc, wie der vielwissende Odunne dem Grafen Riaucour erzählte, auf Beckers Versuch seine Vermittlung am Wiener Hof in der bayerischen Erbfolgefrage in Anspruch zu nehmen, ablehnend: er habe keine Weisung sich in diese Angelegenheit einzumischen ${ }^{3}$ ). Von Lehrbach konnte Riaucour allerdings über die bayeri-

1) Riaucour an Sacken. Schwetzingen 8. Juni 1776. Orig. Dresdener Archiv.

2) Riaucour an Sacken. Schwetzingen 25. Juni 1776. Orig. Dresdener Archiv.

s) Riancour ań Sacken. Schwetzingen 9., 13, Juli; 10. September. Orig. Sacken an Riancour. Dresden 15. September. Concept. Dresdener Archiv. 
sche Erbfolge nichts erfahren; war Kaunitz auch entschlossen, dieser Frage jetzt näher zu treten, so beschränkte er doch die Zahl der Mitwisser des Geheimnisses so viel als nur irgend angängig. Da tauchte abermals der Plan einer Reise Beckers nach Wien auf; als der französische Gesandte am 22. September dem Kurfürsten seine bevorstehende Abreise nach dem königlichen Hoflager zu Fontainebleau ankündigte, teilte ihm Karl Theodor die Absicht seines Mınisters mit und fügte hinzu, er habe dem greisen Staatsmann die schon lange erbetene Erlaubnis nicht versagen können, indes werde Beckers keine politischen Aufträge erhalten. Trotz dieser bestimmt gegebenen Versicherung konnte Odunne seine Missbilligung des ganzen Reiseplanes nicht unterdrücken, denn er kannte den ränkevollen Leiter der pfälzischen Politik viel zu gut, um nicht zu wissen, dass er selbst ein ausdrückliches Verbot von Geschäften zu sprechen entweder unbeachtet lassen oder zu unigehen wissen werde. Der Gesandte stellte dem Kurfürsten vor, wie unzeitgemäss diese Reise sei, sie werde in Dresden, Berlin und München Argwohn erregen und den schon seit längerer Zeit umlaufenden Gerüchten neue Nahrung geben; Karl Theodor jedoch meinte, diese Gerüchte würden verstummen, sobald man sehe, dass Beckers sich nur mit seinen Familienangelegenheiten beschäftige.

Zwei Tage darauf hatte sich die Lage vollkommen geändert. Als Riaucour am 24. September wie jeden Abend in der Hofgesellschaft erschien, sagte ihm der Minister, er habe sich nach eingehender Erwägung des Aufsehens, das sein Vorhaben hervorgerufen, und des Verdachts, den man in Dresden und an anderen Höfen unter den gegenwärtigen Verhältnissen schöpfen könne, entschlossen, seine Reise auf das nächste Frühjahr zu verschieben. Die Besorgnis vor Intriguen seiner Feinde bei Hofe, die seine Abwesenheit benützen könnten, um ihm Unannehmlichkeiten zu bereiten, habe gleichfalls zu diesem Entschluss beigetragen ${ }^{1}$ ).

Es lag natürlich im Interesse Beckers sowohl als der pfälzischen Politik, das Unterbleiben der Reise, das übrigens der Minister selbst von vorneherein mit Rücksicht auf sein Alter und seinen Gesundheitszustand als nicht ausgeschlossen bezeichnet hatte, darzustellen als hervorgegangen aus Beckers eigener Entschliessung. Gewiss hat diese keinen geringen Anteil an der Verschiebung gehabt. Lehrbach, der wach Riaucours Bericht die Mitteilung von der bevorstehenden Reise bei einem kurzen Aufenthalt in Schwetzingen scheinbar kühl und Archiv.

y Riaucour an Sacken. Schwetzingen 24. September 1776. Orig. Dresdener 
gleichgiltig aufnahm, hatte wohl auch schon im Juni von dem Reiseplan Kunde erhalten und darauf bei Kaunitz angefragt, wie er sich dazu stellen solle. Die Antwort lautete vermutlich, er müsse suchen, die Ausführung des Vorhabens zu hintertreiben Jetzt, da die Absicht wirklich ausgeführt werden sollte, stellte Lehrbach dem pfälzischen Minister die Unannehmlichlreiten vor, denen er sich aussetzen werde: die Gefahr liege nahe, dass seine Gegner ihn durch immer neue Instructionen recht lange von Mannheim fernzubalten und ihn allmählich aus dem Ministerium des Auswärtigen zu verdrängen suchen würden. Dass gerade der Freiherr von Hompesch mit seiner Vertretung beauftragt sei, müsse ihm doch die Augen öffnen, denn dieser, mit dem Finanzdepartement längst nicht mehr zufrieden, werde sicherlich mit allen Mitteln die vorübergehend eingenommene Stellung zu behaupten suchen. - Die Vorstellungen machten den gewünschten Eindruck; Beckers erkannte die Berechtigung der geäusserten Besorgnisse an und gab die Reise auf; doch versprach er, da ihm Zerstreuung not thue, den kaiserlichen Gesandten in Frankfurt zu besuchen 1). So berichtet Lehrbach. Dagegen meldet Riaucour, indem er Odunne als Gewährsmann anführt, der Kurfürst habe von Beckers bestimmt die Verschiebung der Reise gefordert 2). - Ganz klar sehen wir hier nicht, denn Lehrbach sowohl wie Odunne sind bei ihren Berichten interessirt; ersterer hatte den Minister durch Schilderung persönlicher Nachtheile, letzterer den Kurfürsten durch Darstellung der politischen Unzuträglichkeiten zum Aufgeben des Planes zu bestimmen gesucht; jeder will sich den Erfolg zuschreiben.

Bei seinem Ausflug nach Frankfurt traf Beckers bei Lehrbach den Geheimen Reichsreferendarius Baron Leykam, der von seinen Gütern im Westpfälischen nach Wien zurückreisend im Hause des Gesandten abgestiegen war. Während des Zusammenseins vom 25. bis 28. September brachte der pfälzische Staatsmann die bayerische und die Jülich-Berg'sche Erbfolge zur Sprache, doch wich Leykam vorsichtig jeder Erörterung aus und vermied es, sich in Abwesenheit Lehrbachs auf politische Gespräche einzulassen. Es liegt kein Grund vor, an der Richtigkeit dieser Darstellung, wie sie Lehrbach in einem Bericht an Kaunitz vom 3. Oktober 1776 gibt, zu zweifeln; umso weniger, als auch Beckers in Mannheim zugibt, er habe keine Gelegenheit gehabt mit Leykam sich zu besprechen.

1) Lehrbach an Kaunitz. Frankfurt a/M. 3. Oktober 1776. Orig. H. H. u. St. A. Staatskanzlei. Berichte aus dem Reich 183. Archiv.

2) Riaucour an Sacken. Schwetzingen 28. September 1776. Orig. Dresdener 
Dennoch rief dieser Ausflug, der intime Verkehr mit Lehrbach, die gleichzeitige Anwesenheit des Reichsreferendarius grosses Aufsehen hervor: sogar der sonst so besonnene Sacken war fest überzeugt, dass man in. Frankfurt sich über wichtige Dinge unterhalten und einen bösen Plan geschmiedet habe ${ }^{1}$ ). Weniger Bedeutung legten Beckers Collegen im Ministerium dem Besuch bei; sie billigten ihn auch keineswegs, da er nur neuen Anlass zu Verdacht und Argwohn gab, ohne irgend welchen Nutzen zu bringen; denn wenn Leykam der kurfürstlichen Regierung Eröffnungen zu machen gehabt hätte, wäre er zweifellos nach Mannheim gekommen. Dieser Ansicht neigte schliesslich auch Riaucour zu; schon die Uneinigkeit innerhalb des pfälzischen Ministeriums machte einen Erfolg der Becker'schen Intriguen wenig wahrscheinlich. Trotzdem liess er nicht nach in seiner Wachsamkeit; die wiederholten Beratungen Beckers mit dem kaiserlichen Gesandten, so oft dieser am pfälzischen Hofe erschien, entgingen ihm nicht; er wandte sich an Freiherrn von Oberndorff, kurfürstlichen Minister des Innern, um, wenn möglich, über den Inhalt der Onterredungen etwas zu erfahren; indes Oberndorff legte ihnen kein Gewicht bei, nach seiner Meinung verhandelte der Wiener Hof nur zum Schein; in Wabrheit beabsichtige er die Dinge in dem bisherigen Zustand der Ungewissheit zu lassen, um bei Eröffnung der bayerischen Erbfolge im Trüben fischen zu können ${ }^{2}$ )

Wie es nun auch um die Verhandlungen stehen mochte, so viel stand überall fest, dass Beckers in Wien als ein brauchbares und williges Werkzeug der österreichischen Politik angesehen wurde; der Kaiserhof selbst gab dies deutlich zu erkennen dadurch, dass bei Gelegenheit des Aufschubes der Reise der Minister im Namen und Auftrag der Kaiserin-Königin aufgefordert wurde, seinen Sohn nach Wien zu schicken, lhre Majestät werde für ihn sorgen und auch sich der Tochter annehmen; es hiess ferner, dass dem Schwager Beckers, dem Geheimen Rat von Huber eine Reichshofratsstelle in Aussicht gestellt worden sei, dass aber Beckers auf eine noch vorteilhaftere Anstellung für ihn im Reichsdienst rechne. Da Lehrbach persönlich von dem Kurfürsten die Erlaubnis erbitten musste, dass der junge Beckers nach Wien gehen dürfe, erregte diese Angelegenheit nicht geringes Aufsehen; die nicht der österreichischen Partei angehörigen Mitglieder der Regierung wunderten sich, dass Karl Theodor die Augen noch immer

1) Sacken an Riaucour. Dresden 8. Oktober 1778. Concept. Dresdener Archiv.

2) Riaucour an Sacken. Schwetzingen 8., Mannheim 22. Oktober 1776. Orig. Dresdener Archiv. 
nicht aufgehen wollten über die vollkommene Abhängigkeit seines leitenden Staatsmannes vom Wiener Hof ${ }^{1}$ ).

In Mannheim hatte man in der That Grund zu glauben, dass der Kaiserhof auf eine Vereinbarung über die bayerische Erbfolge keinen grossen Wert lege. Lehrbach vermied auf diese Frage einzugehen, während er im Geheimen freilich scharf beobachtete, wie man am pfälzischen Hofe darüber dachte. Er konnte berichten, dass der Kurfürst grössere Ergebenheit als je für die Kaiserin-Königin zeige und des Allerhöchsten Schutzes sich würdig zu machen beflissen sei; eine Denkschrift, die Ritter in der Jülich-Berg'schen Successionsangelegenheit überreichen solle, werde dieser Gesinnung Ausdruck geben. Gleichzeitig mit dieser Ankündigung äusserte Karl Theodor von Neuem den Wunsch, dass auch die bayerische Erbfolge bald geregelt werde, da der Gesundheit Maximilian Josephs nicht mehr zu trauen sei. Während aber Lehrbach dort den Kurfürsten in seiner günstigen Stinmung zu bestärken suchte, wurde er hier schweigsam und wich näheren Erörterungen aus ${ }^{2}$ )

In Laufe des November übergab Ritter die in Aussicht gestellte Erklärung der Staatskanzlei; sie wurde gut aufgenommen, doch verlangte man, dass entweder seitens der regierenden Kurfürstin von der Pfalz, die eine Prinzessin von Sulzbach und als solche unmittelbar an der Jülich-Berg'schen Erbfolge beteiligt war, wie von dem Herzog von Zweibrücken als Sohn einer sulzbach'schen Prinzessin, gleichlautende Schriftstücke eingesandt würden, oder dass diese Fürstlichkeiten in besonderen Schreiben an die kaiserlichen Majestäten unter Bezugnahme auf die Erklärung des Kurfürsten die Allerhöchste Verwendung in der fraglichen Angelegenheit nachsuchten. Offenbar hatte dies Verlangen wieder nur den Zweck Zeit zu gewinnen; Kaunitz wollte wahrscheinlich erst die Ansicht des französischen Hofes vernehmen, bevor er mit Kurpfalz sich auf die eine und die andere Frage einliess. Es ist beachtenswert, dass trotz der ersten Anregung Ritters im Frühjahr 1776 bisher noch keine Schritte von Seiten der Wiener Staatskanzlei geschehen zu sein scheinen, um die Stimmung an anderen Höfen zu erkunden.

Beckers geriet durch die Forderung des Wiener Hofes in Verlegenheit; am 4. Dezember schrieb er an den in Mainz weilenden Lehrbach, er wisse nicht, wie er sie, soweit sie den Herzog ron Zwei-

1) Riaucour an Sacken. Mannheim 9. November 1776. Orig. Dresdener Arcbiv.

2) Lehrbach an Kaunitz. Frankfurt a/M. 27. und 30. Oktober 1776. Orig. H. H. u. St. A. 
brücken betreffe, erfü円len solle, denn die Umgebung dieses Fürsten, vielleicht sogar er selbst, seien nicht so gesinnt, dass auf die notwendige Geheimhaltung gerechnet werden könne. Er bat, der Gesandte möge nötigenfalls seinen Einfluss bei dem Herzog geltend machen, um das Bekanntwerden des Geheimnisses zu verhüten; auch wlinschte er sich mit ihm zu besprechen. Lehrbach versprach in seiner Antwort, er werde sein Möglichstes thun, um die Sache zu einem guten Ende zu führen, doch könne er erst nach Neujahr wieder nach Mannheim kommen; er verzögerte absichtlich sein Erscheinen, um vorher neue Instructionen aus Wien einholen zu können. Nicht lange danach erhielt er ein weiteres Schreiben von Beckers (vom 13. Dezember) mit dem Yorschlag, dem Herzog von Zweibrücken solle einstweilen keine Mitteilung gemacht werden, man wolle ihn vielnehr erst nach erfolgter Verständigung zwischen Mannheim und Wien zum Beitritt auffordern. Schwierigkeiten erwartete man von dieser Seite nicht, denn der Herzog hatte erklärt, er werde sich in allen das pfälzische Haus betreffenden Angelegenheiten dem Willen des Kurfürsten fügen ${ }^{1}$ ).

An den europäischen Höfen, die nicht urmittelbar bei der bayerischen Erbfolge beteiligt waren, war, wie gesagt, von Seiten des Wiener Hofes noch ebenso wenig eine Anregung zur Erörterung jener Frage erfolgt, wie bei den Nächstbeteiligten Bayern, Pfalz und Sachsen; denn die bisher gepflogenen Verhandlungen waren von Kurpfalz ausgegangen. Jetzt hielt indes Kaunitz den Zeitpunkt für gekommen, die Stimmung der französischen Regierung zu erforschen; die Reise Kaiser Josephs nach Paris, die in den ersten Tagen des Jahres 1777 angetreten werden sollte, bot eine günstige Gelegenheit. Fr verfasste mit gewohnter Gründlichkeit eine Denkschrift ${ }^{2}$ ), welche dem Kaiser als Instruction dienen sollte, vorausgesetzt, dass er Neigung habe bei seinem Anfenthalt in Versailles sich auf politische Gespräche oder gar diplonatische Verabredungen einzulassen. Dies Aktenstück ist durchaus vertraulicher Natur, sein Inhalt daher von um so grösserer Bedeutung. Es ist keineswegs allein die bayerische Erbfolgefrage, die darin behandelt wird, sie nimmt auch nicht den grössten Raum ein; doch kommt das, was auf sie Bezug hat, allein für diese Untersuchung in Betracht.

1) Lehrbach an Kaunitz. Mainz 10. u. 13, Dezember. Orig. H. H. u. St. A. - Lehrbach an Beckers s. d. et l., Extract, von Riaucour nach Dresden geschickt, Mannheim 21. Dezember 1776. Dresdener Archiv. Loc. 2628 - des Geh. Rats Grafen von Riaucour Abschickung voI. XXX.

ๆ) Sie ist datirt vom 22. Dezember 1776; veroffentlicht von A. Beer im Archiv für österr. Gesch. Bd, 48, 1872. 
Von vornherein lässt Kaunitz keinen Zweifel darüber, dass die von dem Wiener Hof geltend zu machenden Ansprüche auf bayerische Gebietsteile, obwohl an sich gewichtig und einleuchtend, doch noch keineswegs als unanfechtbar bezeichnet werden könnten, denn man wisse ja nicht, ob nicht Pfalz etwa stichhaltige Einwendungen und begründete Gegenansprüche vorzubringen vermöge. Andererseits habe aber auch kein einziger Staat ein Interesse daran, dass Oesterreich sich durch einen Zuwachs an bayerischem Gebiet vergrössere; im Gegenteil sieht er es als sicher an, dass verschiedene Höfe die äussersten Mittel anwenden werden, um diese Machterweiterung zu verhindern. Ein schwerer und höchst gefährlicher Krieg gilt ibm als nahezu unvermeidlich, falls Oesterreich den Besitz Bayerns behaupten wolle; eine Verständigung mit Preussen und Russland könne zwar zu demselben Ziele führen, aber man werde dann dem verhassten preussischen Nachbar einen gleichwertigen Gebietszuwachs gönnen müssen.

Die Ansprüche des Erzhauses, so legt die Denkschrift dar, erstrecken sich nicht auf ganz Bayern, sondern nur auf Niederbayern. Oberbayern kann dagegen als verfallenes Lehen in Sequester genommen und dann auf Grund der Reichsgesetze für den Unterhalt des jeweiligen Kaisers bestimmt werden. Hierzu sind Verhandlungen mit dem Reich, sowie mit verschiedenen deutschen und fremden Höfen erforderlich; da diese aber unabsehbare Weiterungen herbeiführen können, so wird es am zweckmässigsten sein jetzt, da die Erbfolge bereits vielfach erörtert wird und man gar nicht mehr in der Lage ist die Interessenten an Verabredungen untereinander zu hindern, aus der bisherigen Unthätigkeit herauszutreten und die ganze Frage durch eine Vereinbarung mit Kurpfalz aus der Welt zu schaffen. Zweck dieser Vereinbarung soll sein, die beiderseitigen Ansprüche festzustellen und anzuerkeunen, dann aber sogleich dem Erzhaus ein Aequivalent zu bestimmen für Niederbayern, auf das es begründete Ansprüche macht; auch will der Kaiser alsdaun auf die Einziehung der heimgefallenen Reichslehen verzichten. $\mathrm{Zu}$ dem auf dieser Basis zu schliessenden Vertrag wird die Zustimmung Frankreichs und anderer unparteiisch denkender Höfe leicht zu erhalten sein, während der König von Preussen ganz aus dem Spiel gehalten wird. Am meisten erwünscht wären nun für Oesterreich als Aequivalent die zwischen Inn und Donau gelegenen bayerischen Besitzungen, sowie die Oberpfalz mit Neuburg und Sulzbach; für die letztgenannten beiden Herzogtümer könnte vielleicht ein Teil der österreichischen Vorlande abgetreten oder die Zahlung einer mässigen Geldsumme an Sachsen wegen seiner Allodialansprüche übernommen werden. 
Diese Abrundung des österreichischen Länderbesitzes verschafft dem Erzhaus zugleich eine Vermehrung seiner Einkünfte, besonders wichtig aber ist, dass die Zustimmung des Reichs und der fremden Höfe kaum bezweifelt werden kann. In jeder Beziehung ist also dieser Plan vorteilhaft und auch einem etwaigen Austausch des ganzen Herzogtums Bayern gegen die Niederlande vorzuziehen. - Soweit die Denkschrift.

Unter den fremden Mächten, deren Zustimmung für das Gelingen des Kaunitz'schen Planes wichtig war, stand Frankreich obenan. Als Garant des Westpfälischen Friedens hatte der Nachfolger Ludwig XIV. die Möglichkeit sich bei jeder Gelegenheit in die Angelegenheiten des Deutschen Reichs einzumischen; aber auch als Verbündeter Oesterreichs konnte er verlangen, dass ihm von so weittragenden Plänen frühzeitig Mitteilung gemacht werde. Mit dieser Mitteilung nun gedachte Kaunitz den Kaiser zu beauftragen, zugleich sollte er die Verhandlungen ïber Frankreichs Einwilligung in Gang bringen.

Gewiss bedauerte es der Staatskanzler aufs Tiefste, als der Kaiser seine Reise bis zum Frühjahr hinausschob; eine Gelegenheit zur Anknüpfung, wie sie günstiger kaum gedacht werden konnte, ging dadurch verloren; denn die Eröffnungen an den Versailler Hof abermals um ein Vierteljahr zu verzögern, den Kurfürsten von der Pfalz noch länger hinzuhalten schien bedenklich; so musste der regelmässige diplomatische Weg betreten werden, um die Unterhandlung einzuleiten.

Der Vertreter des Kaiserhofes in Frankreich war ein langjähriger Vertrauter der Kaiserin-Königin, Graf Mercy-Argenteau, dem auch der Staatskanzler unbedingtes Vertrauen schenkte. An ihn erging bald nach dem Aufschub der Reise des Kuisers der Befehl, bei der ersten günstigen Gelegenhert die bayerische Erbfolge zur Sprache zu bringen. Ein Gespräch mit dem Minister des Auswärtigen, Grafen Vergennes über die Erbfolge in Jülich-Berg bot bald den gesuchten Anknüpfungspunkt; Mercy sprach den Wunsch aus, dass gleich zeitig mit jener Frage ein Uebereinkommen wegen der bayerischen Succession getroffen werde; der König von Preussen habe dieserhalb dem Wiener Hof bereits böse Absichten angedichtet und auch andere Staaten entfalteten schon eine emsige Thätigkeit, während man in Wien bisher den Fall als noch zu fern liegend angesehen habe, um Vorkehrungen zu treffen. Indes scheine es jetzt an der Zeit zu sein, mit der Sprache herauszuräcken und zugleich dem Verbündeten Mitteilung zu machen.

Längst schon hatte das Versailler Cabinet den über den Rhein herüber dringenden Gerüchten von Verhandlungen zwischen den an der bayerischen Erbschaft Beteiligten Aufmerksamkeit geschenkt; der tranzösische Gesandte in Mannheim, Odunne war durch vortreffliche 
Verbindungen im Stande, manche wertvolle Nachricht nach Versailles gelangen zu lassen und seine Haltung beweist, dass das französische Ministerium, bevor es officiell durch Mercy von dem Stand der Dinge Kenntnis erhielt, seine Ansicht sich bereits gebildet hatte. Doch hielt es Vergennes nicht für zweckmässig, Mercy seine eingehende Bekanntschaft mit der Frage zu verraten: er schützte mangelhafte Kenntnis der deutschen Reichsverfassung vor, um die sofortige Beantwortung zu umgehen. Der Botschafter legte ihm nun dar, dass die Frage mit Hilfe des Reichslehenrechts, der Bestimmungen des Westpfälischen Friedens und der kaiserlichen Wahlkapitulation leicht und einfach zu lösen sei; danach habe Kurpfalz nur Anspruch auf die fünfte Kurwürde und auf die Oberpfalz; alles Uebrige sei Lehen und zwar Reichslehen, das mit Zustimmung des Reichs entweder neu vergeben oder als ein beständiges Domanium für den jeweiligen Kaiser verwendet werden müsse, - oder aber Lehen der Krone Böhmen und anderer Staaten. Ganz so einfach schien der Sachverhalt dem französischen Illinister indes doch wicht zu sein; er entgegnete, seiner Ansicht nach träten beim Erlöschen emer Linie die Agnaten aus der andern Linie sofort als Erben ein; auch müsse man auf die Hausverträge Rücksicht nehmen. Mercy versetzte schlagfertig. der Eintritt der Agnaten sei nur möglich, wenn sie die Mitbelehnung empfangen hätten; was aber die Hausverträge betreffe, so seien sie nur gültig, soweit sie die Rechte Dritter nicht schädigten - vorausgesetzt, dass sie in Folge der Bestätigung durch Kaiser und Reich überhaupt reichsrechtliche Giltigkeit besässen.

So bestimmt Mercy auch die Einwände des Ministers zurückwies, so wenig vermochte er ihn zu überzeugen; er hielt es schliesslich bei der sichtlichen Verstimmtheit Vergennes für ratsan, zunächst sich mit den gemachten Andeutungen zu begnügen , und das hiesige Ministerium nicht auf einmal allzu schüchtern machen zu sollen, massen es solchergestalten den gauzen Umfang unserer Anspriiche nicht einsiebet und uns gleichwohl keiner Verschlossenheit beschuldigen kann."

Entsprach schon die Aufnahme dieser einleitenden Eröffnungen den Wünschen des Wiener Hofes durchaus nicht, so zeigten die Aeusserungen des französischen Botschafters in Wien, der sich damals gerade in Paris auf Urlaub befand, dass Oesterreich mit seinen bayerischen Plänen bei Frankreich auf starken Widerstand stossen werde. Baron Breteuil machte gegen Mercys Vorbringen dieselben Einwendungen wie Vergennes, und als der Vertreter Maria Theresias die Agnatenerbfolge und die Gültigkeit der Hausverträge auch ihm gegenüber nur bedingt zugeben wollte, erklärte er, mit solehen Grundsätzen werde man das 
ganze deutsche Reichssystem umstürzen. In seinem Bericht an Kaunitz bemerkte Mercy, es gebe nur zwei Arten der Erklärung für die Haltung der französischen Staasmänner: entweder sei die bayerische Erbfolgefrage schon von andrer Seite in Oesterreichfeindlichem Sinne angeregt worden oder die leitenden Grundsätze seien in Paris durchaus verschieden von denjenigen. die man in Wien befolge ${ }^{1}$ ).

Aber noch eine andere Erfahrung machte Mercy, die ihm ebenfalls peinlich war: immer deutlicher zeigte sich das Bestreben Vergennes alle wichtigeren diplomatischen Verhandlungen von Versailles weg an die fremden Höfe zn verlegen, wo sie von den französischen Gesandten geführt werden sollten. Als der pfälzische Gesandte Graf Sickingen mit dem Minister über die Jülich-Berg'sche Frage sprechen wollte, erhielt er den Bescheid, Breteuil, der bald nach Wien zurückkehre, sei mit den nötigen Weisungen versehen; fast ängstlich wich Vergennes jedem Zusammentreffen mit dem kaiserlichen Botschafter aus, das zu eingehenden Auseinandersetzungen Gelegenheit geboten hätte.

Am 24. März trat Breteuil die Rückreise nach Wien an; seine Instruction legt Zeugnis ab von der in den französischen Regierungskreisen herrschenden Verstimmung gegen den Kaiserhof ${ }^{2}$ ). Das gemeinsame Vorgehen Mercys und Sickingens in der Jülich-Berg'schen Angelegenheit hatte nämlich in Paris den Verdacht erweckt, als ob bereits seit längerer Zeit Verhandlungen zwischen Mannheim und Wien im Gange seien, die man ror dem Alliirten geheimgehalten habe. Ja, man glaubte sich zu dem Vorwurf berechtigt, Oesterreich habe bisher stets nur seine eigenen Interessen verfolgt, selbst wenn sie zu denen des Bundesgenossen im Gegensatz standen; es habe sogar nach alter Gewohnheit bei den meisten Unterhandlungen Frankreichs im Ausland, zumal an den deutschen Höfen, dessen Absichten bald offen, bald insgeheim bekämpft. Doch gestand die Instruction auch wieder zu, dass seit dem bedrohlichen Vorgehen der Russen auf der Krim darin eine bedeutsame Veränderung zum Besseren eingetreten sei und zwar wesentlich durch die freimütige Eröffnung des österreichischen Ministeriums über alle wichtigeren Fragen der internationalen Politik, die dann den Anstoss zu einem Meinungsaustansch und zu lebhafterem diplomatischen Verkehr gegeben habe. Die Frage nun, welche zur Zeit der Reise Breteuils im Vordergrund des Interesses stand, war die

1) Mercy an Kaunitz. Paris 19. Februar 1777. Orig. H. H. u. St. A. Frankreich. Correspondenz 208.

2) Instruction für Breteuil vom 2. März 1777. Recusil des Instructions t. I. Autriche p. $501 \mathrm{ff}$. 
orientalische; an ihrer Lösung war Oesterreich als Nachbar Russlands und der Türkei nahe beteiligt. Das Verhältnis zu Preussen trat für die Wiener Staatsmänner hinter jene brennende Frage kaum für einen Augenblick zurück. Erst in dritter Linie kam das Interesse Oesterreichs an der Succession in Jülich-Berg und an der bayerischen Erbfolge. Ueber diese Punkte hatte der Wiener Hof dem Grafen Vergennes durch Mercy seine Ansicht aussprechen lassen; Breteuil sollte die Antwort darnuf überbringen.

Die für uns vorwiegend in Betracht kommende bayerische Erbfolgefrage erfährt in dieser Antwort eine sehr kurze Abfertigung, sie wird bezeichnet als eine noch im Stadium theoretischer Erörterungen befindliche Angelegenheit, über die das französische Ministerium weitere Aufk]ärungen erwarte, bevor es eingehender dem König berichten und dem Botschafter Weisung geben könne. Vergleicht man diese knappe Erwähnung mit der ausführlichen Besprechung der Jülich-Berg'schen Succession in Breteuils Instruction, so ergibt sich, dass Vergennes nicht gewillt war sich mit den dürftigen Andeutungen Mercys vom Februar zu begnügen, dass er aber auch keineswegs die Regelung der bayerischen Erbfolge für besonders dringlich bielt. Offenbar war ihm das Aufwerfen dieser Frage in dem gegenwärtigen Augenblick, da die Aufmerksamkeit Frankreichs ebenso sehr von den Vorgängen in der Krim wie in den amerikanischen Colonien in Anspruch genommen wurde, recht unbequem. Im Ganzen genommen war man aber doch zufrieden, dass der Kaiserhof sich endlich einmal offen und vertrauensvoll an seinen Alliirten gewendet hatte; deshalb wurde Breteul angewieseu, durch freimütige Aussprache, wenn möglich, die Anknüpfung einer vertraulichen Corresponảenz herbeizuführen und so allen bisher recht zahlreichen Missverständnissen vorzubeugen.

So also lagen die Dinge, als Kaiser Josef in den letzten Tagen des März 1777 die Reise nach Frankreich antrat. Schon in ruhigen Zeitläuften hätte dieses Ereignis die Blicke von ganz Europa auf sich gelenkt; um wie viel mehr musste dies der Fall sein in einem Augenblick, da im Usten und im Westen des Weltteils schwere Gewitterwolken am politischen Himmel den Ausbruch blutiger Kriege anzukündigen schienen, da im Innern des deutschen Reichs in Folge des Scheiterns der Kammergerichtsvisitation die Spannung zwischen Kathollken und Protestanten einen bedenklich hohen Grad erreicht hatte!

Es scheint fast, als habe man in Versailles Kenntnis gehabt von der Kaunitz'schen Denkschrift vom Dezember des Vorjahrs und von dem $Z$ weck, den sie verfolgte. Schon hatte Joseph die französische 
Grenze überschritten, da verfasste auch Vergennes eine Instruction für seinen jungen, noch unerfahrenen Monarchen, um ihn zu warnen vor den Fallstricken seines hohen Gastes. Da man Joseph die Absicht zuschrieb den Einfluss seiner Schwester, der Königin Maria Antoinette zu vergrössern und durch sie den Herzog von Choiseul und den Baron Breteuil ins Ministerium zu bringen, war der Ton der Denkschrift ziemlich gereizt. Auch in ihr missbilligt der Minister aufs Schärfste die Art, wie die Allianz von Oesterreich bisher missbraucht worden sei, wie der Wiener Hof das Vertrauen der deutschen Fürsten auf Frankreichs Beistand bei der Verteidigung ihrer Rechte zu untergraben gesucht habe. Er legt die Ungleichheit der Vorteile dar, welche die Allianz ihren Theilnehmern biete und warnt davor, neue Verpflichtungen zu übernehmen, etwa des Inhalts, dass Frankreich im Notfall Oesterreich mit allen seinen Mitteln unterstütze. Das Ziel des Wiener Hofes könne bei solchen Forderungen immer nur die Vernichtung Preussens sein; gerade dieser Staat sei aber das letzte Bollwerk gegen den österreichischen Ehrgeiz, das Frankreich in seinem eigenen Interesse aufrecht erhalten müsse. Eben dieses Interesse Frankreichs verbiete auch eine Vergrösserung der österreichischen Macht, die selbst bei der Hingabe der Niederlande oder Vorderösterreichs als Aequivalent zu unermesslichem Schaden Frankreichs ausschlagen werde. Die Bewahrung des bestehenden Zustandes in Mitteleuropa, die Erhaltung des Gleichgewichts der Mächte wird von Vergennes als der leitende Gedanke der französischen Politik hingestellt.

Doch die Besorgnisse des Ministers vor gefährlichen Plänen Josephs erwiesen sich als unbegründet; der Kaiser kam nach Frankreich, um seine Schwester wieder zu sehen, seinen Schwager und den französischen Hof kennen zu lernen; die Absicht Politik zu treiben Jag ihm fern. Und so ist auch wahrscheinlich die bayerische Erbfolgefrage bei seinem Aufenthalt in Versailles gar nicht einmal ausführlich erörtert worden 1).

Während der Abwesenheit Josephs von Wien wurden in der Staatskanzlei alle Vorbereitungen getroffen, um nach der Rückkehr des Monarchen die Entscheidung über die weitere Behandlung sowohl der Jülich-Berg'schen als der bayerischen Erbfolge herbeizufühen. Ein lebhafter Meinungsaustausch mit dem pfälzischen Hofe hatte bereits

1) Vergleiche Riancours Schreiben an Stutterheim. Mannheim 7. Juni 1777. Orig.; on prétend au reste qu'il sera très-difficile d'approfondir si l'Empereur a parlé d'affaire en France et que tout ce qu'on avance là-dessus n'est fondé que sur des conjectures incertaines. Driesdener Archiv. 
wesentlich zur Klarstellung der beiderseitigen Ansprüche beigetragen. Die Antwort des Wiener Ministeriums auf die pfälzische Anregung in der Jülich-Berg'schen Angelegenheit vom November 1776 hatte, wie erwähnt, entgegenkommend gelautet; Kurfürst Karl Theodor hatte daraus Anlass genommen in seinem Dankschreiben den Wunsch auszusprechen, „dass Sie ebenmässige gewührigste Neigung zu der Ihro nicht weniger am Herzen liegenden friedlichen Berichtigung über die eventuale bayerische Erbfolge Sich zu getrösten haben mögten". Als auch hierauf eine günstige Antwort erfolgte, erklärte Karl Theodor, dass er in beiden Angelegenheiten sein ganzes Vertrauen auf den Wiener Hof setze (am 14. Februar 1777) und wies seinen Gesandten Freiherrn von Ritter an sich in diesem Sinne zu äussern ${ }^{1}$ ); einen unzweideutigen Beweis dieser Gesinnung gab dann Beckers, indem er dem Freiherrn von Lehrbach einen Auszug aus der sehr umfangreichen Denkschrift des pfälzischen Staatsrats von Cuntzmann übermitteln liess, worin die Ansprüche des Kurfürsten auf die bayerische Erbschaft dargelegt und rechtlich begründet wurden, die zugleich aber auch die Mittel und Wege angab, wie Kurpfalz in den Besitz des Erbes gelangen könne. Das alleinige Heil sieht der Verfasser jetzt, nachdem er früher anderer Ansicht gewesen war, in rückbaltlosem Anschluss an den Kaiser; schon die Klugheit gebiete dies Verhalten, denn die kaiserlichen Ansprüche auf die unmittelbaren Reichslehen seien begründet und ihre Geltendmachung werde zu den grössten Unbequemlichkeiten für Kurpfalz führen; auch könne der Wiener Hof sehr zum Nachteil von Pfalz die kursächsischen Ansprüche auf das Allodium unterstützen. Die Denkschrift empfiehlt einen Gebietsaustausch: Karl Theodor erhält die Reichslehen, die im Besitz der bayerischen Linie gewesen sind, und gibt dafür das Land jenseits des Inns ganz oder zum Teil an Oesterreich ab. Der Wiener Hof soll auch versprechen, sich in Berlin für die Erneuerung der preussischen Garantie wegen der sulzbach'schen Nachfolge in Jülich-Berg zu verwenden. - Es war das Programm, der Operationsplan des kurpfälzischen Hofes, den Beckers dem kaiserlichen Gesandten überlieferte ${ }^{2}$ ).

1) Es ist nicht ausgeschlossen, dass das Dankschreiben Karl Theodors mit dem Schreiben vom 14. Februar, die erwähnte günstige Antwort mit der auf die Anregung vom November 1776 erfolgten identisch ist; die Akten, denen ich hier folge, drücken sich nicht deutlich aus. Uebrigens scheint mir die Frage, ob ein oder zwei Schreiben ergangen sind, von nur geringer Bedeutung zu sein.

2) Lehrbach an Kaunitz, Mainz 4. März 1777, sendet den ihm zugesandten Auszug, der, von einer vertrauten Person in grosser Eile ohne Jemandes Vorwissen angefertigt worden" sei. H. H. u. St. A. 
Da an der Aufrichtigkeit Karl Theodors und seines leitenden Staatsmannes nach einer so weitgehənden Eröffnung nicht mehr zu zweifeln war, beantragte Kaunitz am 15. März in einem der KaiserinKönigin gehaltenen Vortrage, dem Kurfürsten nun auch diejenigen Ansprüche mitzuteilen, welche das Erzhaus Oesterreich an die bayerische Erbschaft zu haben glaube; dadurch erwidere man das Vertrauen und beuge zugleich nachteiligen Uebertreibungen vor, an denen es die Gegner schwerlich fehlen lassen würden. Mit dieser Aufgabe wurde Binder, der treue Gehülfe des Staatskanzlers, betraut; er übergab Ritter zwei Denkschriften, deren eine den Nachweis führte, dass die bayerischen Lande nach dem Erlöschen des wilhelminischen Mannesstammes als eröffnete Reichslehen zu betrachten seien, während die andern die österreichischen Ansprüche auf einige Teile Bayerns darlegte 1). Mündlich machte Binder dazu die Bemerkung: „dass nur das vertrauliche kurfürstliche Benehmen das kaiserliche Ministerium bewogen hätte über einen Gegenstand so offenmütig zu Werke zu gehen, welchen man ansonsten bis auf den sich ergebenden Fall beruhen und dem ,diesseitigen Gerechtsamen günstig glaubenden Schicksale zu überlassen gemeinet gewesen wäre " ${ }^{2}$ ).

Die pfälzische Antwort auf diese Eröffnung liess lange auf sich warten; erst Anfang Juli übergab Ritter eine Widerlegung der beiden Aufsätze. Die Behauptung, dass das Fehlen der gleichzeitigen Investitur der rudolphinischen Linie den Rückfall der bayerischen Lande an das Reich nach sich ziehe, liess man in Mannheim nicht gelten; man suchte zu beweisen, dass allein das Recht der gemeinsamen Abstammung entscheide und dass demnach das Herzogtum Bayern an Kurpfalz fallen müsse. Nicht so bestimmt sprach man sich über die Ansprüche von Kaiser und Reich auf die Neoacquisita und über die österreichischen Ansprüche aus ${ }^{3}$ ). Gegen die hier vorgebrachten Einwendungen richtete sich eine Erwiderung der Staatskanzlei; dem weiteren Notenwechsel gingen mündliche Besprechungen mit Ritter zur Seite; dabei machte der Gesandte auch einmal den Vorschlag, Oesterreich möge die ganze bayerische Erbschaft einschliesslich der Oberpfalz, sowie die Herzogtümer Neuburg und Sulzbach nehmen und dafür ein angemessenes Aequivalent geben, doch zog er sich durch seinen Ueber-

1) Vergl. Beer in der hist. Ztschrft. Band 35 S. 96 und Arneth, Maria Theresia Bd. 10, S. 296.

2) Denkschrift Ritters. Wien 14. Januar 1778. Orig. Bayer. Geh. St. A. K. schw. 329/32.

3) Kaunitz Vortrag vor Maria Theresia rom 23. August 1777. Orig. H. H. u. St. A. Vorträge 176 . 
eifer einen scharfen Verweis seines Vorgesetzten zu, da von einer Abtretung der.Oberpfalz, Neuburgs und Sulzbachs niemals die Rede sein könne, sondern nur von der Hingabe Ober- und Niederbayerns.

Soweit waren die Verhandlungen gediehen, als Kaunitz der KaiserinKönigin den entscheidenden Vortrag rom 23. August hielt.

Obwohl man in Wien und Mannheim über alle Verhandlungen, die auf die bayerische Erbschaft Bezug hatten, das grösste Geheimnis walten liess, drangen doch mancherlei Gerüchte in die Oeffentlichkeit. Gegen Ende Mai erfuhr Riaucour, dass die Differenzen Kursachsens mit dem böhmischen Lehenshof wegen der Grafschaft Schoenburg Beckers Anlass gegeben hätten ein Abkommen über die bayerische Erbschaft in Wien anzuregen - übrigens ein Lieblingsplan dieses Ministers - und dass man österreichischerseits jetzt nicht melir die frühere Abneigung gegen diese Regelung zu zeigen scheine; bald wurde ihm Niederbayern oder das Land östlich des Inns als dasjenige Gebiet bezeichnet, welches auf Grund eines kürzlich getroffenen Abkommens an Oesterreich fallen sollte 1). Gar manche Anzeichen sprachen für die Richtigkeit dieser Angaben; Lehrbach wurde am kurfürstlichen Hoflager zu Schwetzingen zuvorkommender als je empfangen und auch an den üblichen vertraulichen Besprechungen mit Beckers fehlte es nicht, als er rom 21. bis 26. Mai sich in Mannheim aufhielt. Auch die Reise, die er fast unmittelbar danach zu dem Herzog Karl von Zweibrücken unternahm (31. Mai bis 3. Juni), um sein Beglaubigungsschreiben zu überreichen, konnte so gedeutet werden, als ob er die Zustimmung des nach Karl Theodor nächsten Erbberechtigten zu einer Vereinbarung einholen wolle. Aber der Schein trog: Lehrbach spielte in dieser Angelegenheit nur eine untergeordnete Rolle, die Verhandlungen über die Regelung der bayerischen Erbfolge wurden in Wien geführt. In Mannheim war davon höchstens ganz im Allgemeinen die Rede, in Jaegersburg, dem herzoglichen Jagdschloss, vielleicht überhaupt nicht. Trotzdem ist Lehrbachs Besuch durchaus nicht ohne Bedeutung, insofern nämlich als der Gesandte die Vermittlerrolle übernommen hatte zwischen den augenblicklich auf gespanntem Fuss mit einander stehenden Höfen von Mannheim und Zweibrücken; es gelang ihm durch offene Aussprache mit dem Herzog eine Wiederannäherung zu erwirken, die bald nachher zu vollständiger Aussöhnung führte $\left.{ }^{2}\right)$. Da der Herzog bisher eine starke Hinneigung zu Frank-

1) Riaucour an Stutterheim. Mannheim 27. u. 31. Mai 1777. Orig. Nr. 43 u. 44. Dresdener Archiv.

2) Lehrbach an Kaunitz. Mainz 7. Juni, Mannheim 17. Juli 1777. Orig. H. H. u. St. A, 
reich gezeigt hatte, von wo er beträchtliche und bei seiner leichtsinnigen Finanzwirthschaft kaum zu entbehrende Hilfsgelder erhielt, das französische Ministerium aber den österreichischen Ansprüchen auf Bayern nicht günstig gesinnt war, konnte die Versöhnung mit Kurpfalz, das sich dem Wiener Hofe in die Arme geworfen hatte, zugleich als eine Annäherung an diesen gelten, und die Gefahr, dass Frankreich sich des Herzogs zur Durchkreuzung der österreichischen Pläne bedienen werde, war dadurch verringert. - Noch mehrmals tauchten im Laufe des Sommers 1777 Gerüchte von Verabredungen zwischen Pfalz und Oesterreich in Mannheim auf, indes stellte sich jedesmal bald heraus, dass sie wenig Wahrscheinlichkeit besassen.

Am 1. August, dem Tage, da Joseph von seiner Reise wieder in die österreichische Hauptstadt zurückkehrte, hatte Kaunitz bereits bei der Kaiserin-Königin in Anregung gebracht, dass der pfälzische Gesandte Freiherr von Ritter bei seinem Hofe um die Erlaubnis nachsuche, sich zu persönlicher Berichterstattung und Empfangnahme von Weisungen nach Mannheim begeben zu dürfen; er begründete seinen Antrag damit, dass die Vorbereitungen und Ausarbeitungen weit genug vorgeschritten seien, um demnächst der Allerhöchsten Beurteilung und Entscheidung vorgelegt zu werden ${ }^{1}$ ). Maria Theresia gab ihre Einwilligung, Ritter fragte in Mannheim an und exhielt umgehend die erbetene Erlaubnis.

Auf Grund der inzwischen beendeten Vorarbeiten trug nun der Staatskanzler am 23. August die bayerische Erbfolgefrage in ihrer geschichtlichen Entwicklung seiner Monarchin vor, er legte die augenblickliche Sachlage dar und knüpfte daran eine Reihe von Fragen, deren Beantwortung für das weitere Verhalten des Wiener Hofes entscheidend werden musste; er verfehlte indes nicht jedes Mal gleich diejenige Antwort hinzuzufügen, welche seiner Ansicht nach die einzig richtige war. Den wesentlichen Inhalt hat Arneth in seiner Geschichte Maria Theresias mitgetheilt ${ }^{2}$ ); ich begü̈ge mich die von Kaunitz gefundenen Ergebnisse aus den vielseitigen Ueberlegungen kurz zusammen zu fassen. Der Staatskanzler rät nicht den Tod Maximilian Josephs abzuwarten, um Oesterreichs und des Kaisers Rechte geltend zu machen, sondern vorher und zwar möglichst bald eine Convention mit dem pfälzischen Hofe abzuschliessen. Darin soll Karl Theodor die Ansprüche des Erzhauses auf Niederbayern und Mindelheim anerkennen, wogegen Oesterreich die pfälzische Besitzergreifung Ober-

1) Vortrag Kaunitz' vom 1. August 1777. H. H. u. St. A.

2) Band 10. Seite 297-301. 
bayerns, allenfalls auch der Neoaquisita zuzulassen verspricht. Demnach werde der Vertrag nichts anderes enthalten als eine wechselseitige Anerkennung der beiderseits herabgeminderten und in Uebereinstimmung gebrachten Rechtsansprüche auf die bayerische Erbschaft; trete Karl Theodor dann mehr Gehiet ab, als er durch die Convention verpflichtet sei, so werde er - aber nur dafür - ein Aequivalent erhalten; doch müsse dies späterer Vereinbarung vorbehalten bleiben. Diese Regelung auf Grund der beiderseits anerkannten Ansprüche zieht Kaunitz als die einfachste jeder anderen Lösung der Frage vor, weil dabei kein Aequivalent erforderlich ist. Die Schwierigkeiten, die sich der Beschaffung eines passenden Ausgleichsobjectes bei der Abtretung von Oberbayern, Oberpfalz, Sulzbach und Neuburg oder auch nur bei der Ueberlassung des Herzogtums Oberbayern an Oesterreich entgegen stellen, hält er für so gross, dass er von diesen Plänen abzusehen empfiehlt ' ). Auf Grund dieser Darlegung erbat und erhielt Kaunitz die Erlaubnis der Kaiserin, die auf den Abschluss einer Convention abzielenden Verhandlungen mit Kurpfalz fortzusetzen; auch der Kaiser gab seine Zustimmung.

Alle rechtlichen und politischen Bedenken, welche gegen die Ansprüche des Hauses Oesterreich auf die bayerische Hinterlassenschaft etwa vorgebracht werden konnten, fasste der Staatskanzler in einem weiteren Vortrag (vom 24. August) zusammen; bei der schriftlichen Ausarbeitung findet sich die Bemerkung: „Auf hohen Befehl Niemandem zu communiziren " 2). Offenbar wollte er seinen Antrag rechtfertigen, in einem Vergleich einen Theil der Ansprüche aufzugeben, anstatt auf dem Recht in vollem Umfang zu bestehen. Auf seinen Wunsch wurde nun auch die Reichskanzlei von der bevorstehenden Unterhandlung in Kenntnis gesetzt und zwar geschah dies durch ein kaiserliches Schreiben an den Fürsten Colloredo, worin Joseph unter Einschärfung strengster Verschwiegenheit befiehlt sich mit der Staatskanzlei in Verbindung zu setzen ${ }^{3}$ ).

Nachdem Maria Theresia die von Kaunitz vorgeschlagenen Grundsätze genehmigt und ihm die Fortführung der Verhandlung mit Ritter völlig überlassen hatte, waren noch weitere wichtige Entscheidungen zu treffen, nämlich ob man Frankreich von der Unterhandlung Kenntnis geben, wann und in welchem Umfange dies geschehen solle. Eine vorläufige Mitteilung allgemeiner Art war ja schon im Februar durch

') Vortrag Kaunitz' vom 23. August 1777. H. H. u. St. A.

2) Vergl. Beer, hist. Ztschr. Bd. 35 S. 99/100.

s) Der Kaiser an Colloredo 2. September 1777. Beer, hist. Ztschr.Bd. 35 S. 100. 
Mercy gemacht worden; Vergennes hatte aber damals, wie erwähnt, die Besprechung der bayerischen Frage zu vermeiden gesucht und den Wiener Hof an Breteuil gewiesen. Bald nach der Rückkehr des Botschafters nach Wien, die am 9. April erfolgte, hatte dann Kaunitz mit ihm eine Besprechung über die bayerische Erbfolge gehabt und darin ausgeführt, Oesterreich böten sich zwei Wege zum Ziel: entweder warte es den Tod des Kurfürsten Maximilian Joseph ab oder es regle vor dem Eintritt dieses Ereignisses die ganze Angelegenheit durch eine Vereinbarung mit Kurpfalz. Die Ende Mai erteilte offizielle Antwort des Botschafters hatte sich darauf für den Weg des Vergleichs ausgesprochen und die Mitwirkung Frankreichs zur Herbeiführung eines Arrangements angeboten. Mit Dank waren die Anzeichen einer entgegenkommenderen Stimmung in Wien begrüsst worden und Mercy hatte Weisung erhalten, im Namen der Kaiserin diesem Dank für die freundschaftlichen Eröffnungen Breteuils Ausdruck zu geben und die Zusicherung zu erteilen, dass der Wiener Hof sich mit dem französischen Ministerium über alle ferneren Massnahmen in vertrauliches Einvernehmen setzen werde ${ }^{1}$ ). Nachdem inzwischen die Vorverhandlnngen mit Ritter stattgefunden hatten, während deren keine weitere Eröffnung in Versailles erfolgt war, beantragte jetzt der Staatskanzler, die französische Regierung sogleich rückhaltlos von der geplanten Unterhandlung zu benachrichtigen und die wegen der Jülich-Berg'schen Garantieerneuerung doch notwendige Ministerialäusserung an Kurpfalz als Anlass und Anknüpfungspunkt zu bezeichnen, wie dies Vergennes selbst als zweckmässig empfohlen habe. Für ihn war die Annahme massgebend, dass Karl Theodor sich ohne Einwilligung des französischen Ministeriums überhaupt wohl kaum anf Vereinbarungen von solcher Tragweite wie die geplanten, einlassen werde; er hoffte aber auch, dass Kurpfalz die österreichischen Vorschläge eher annehme, wenn sie vorher in Versailles gebilligt worden seien. Zugleich konnte er dann, Frankreichs Zustimmung sicher, etwaigem Widerspruch von andrer Seite zuversichtlicher entgegen sehen. Indes wollte er den französischen Hof doch nicht mehr als das Nötigste erfahren lassen; Mercy sollte nur darlegen, welche Ansprüche Oesterreich auf Niederbayern, Mindelheim und die böhmischen Lehen geltend mache und wie es gegen deren Anerkennung auf pfälzischer Seite das Recht der gemeinsamen Abstammung und die daraus zu ziehenden Folgerungen zulassen wolle.

1) Mercy an Kaunitz. Paris - das Datum fehlt, da von der Depesche nur der erste Bogen vorhanden ist - wohl 22. Juni 1777; präsentirt Wien 29. Juni. Orig. H. H. u. St. A. Frankreich 208. 
Am 21. September erhielt Ritter die Antwort der Staatskanzlei auf sein Memoire vom 22. Mai wegen der Erneuerung der preussischpfälzischen Convention von 1741 über die Jülich-Berg'sche Erbfolge 1), kurz darauf verliess er Wien und begab sich nach Mannheim; etwa Mitte November gedachte er auf seinen Posten zurückzukehren. Er durfte dem Kurfürsten mitteilen, der Kaiserhof werde, sobald Kurpfalz die Grundzüge der Vereinbarung angenommen und die österreichischen Ansprüche auf Niederbayern uad Mindelheim anerkannt habe, nicht abgeneigt sein ,in ein der beiderseitigen Convenienz angemessenes Arrangement oder Austausch dieser Forderung nach ibrem Wert einzugehen." Auch mit anderen Versprechungen waren Kaunitz und Colloredo nicht sparsam gewesen, als Ritter sich bei ihnen verabschiedet hatte; besonders erwünscht musste Kurpfalz das Versprechen der beiden Staatsmänner sein hinwirken zu wollen auf die ,vorteilhafteste Behandlung “, d. h. natürlich auf die möglichste Einschränkung der sächsischen Allodialforderungen, und auch die zur Schau getragene Neigung, die böhmischen Lehen an Kurpfalz zu vergeben, war nicht gering anzuschlagen ${ }^{2}$ ).

Während der Anwesenheit Ritters in Mannhein trat dort ein Ereignis ein, welches für das Schicksal der Unterhandlung in gewissem Sinne verhängnisvoll wurde: am 31. Oktober starb plötzlich der pfälzische Minister Freiherr von Beckers, die Seele der Oesterreich-freundlichen Politik und eigentlich auch deren einziger Vertreter innerhalb des Ministeriums. Da er die Verhandlungen mit dem Wiener Hof ohne Zuziehung der übrigen Minister und nur mit Hülfe seines Schwagers, des Geheimen Rates von Huber geführt hatte, war ausser dem Kurfürsten Niemand in den Stand der Dinge eingeweiht. Auf die Wahl eines gewandten Nachfolgers, der zugleich den Beifall des Kaiserhofes hatte, kam daher viel an, und doch gestatteten die Verhältnisse keine lange Erwägung; rasche Besetzung des erledigten Ministerpostens war notwendig, wenn nicht die Ränke der Sickingen'schen Partei einen ungünstigen Einfluss ausüben sollten. Schon am 2. November betraute Karl Theodor seinen Oberst-Stallmeister, den Staats- und Conferenzminister Freiherrn von Vieregg mit der einstweiligen Leitung der auswärtigen Angelegenheiten. Wenngleich Vieregg nichts von Geschäften verstand und deshalb den Auftrag nur ungern annahm, war seine Wahl keine schlechte; die Persönlichkeit des Neuernannten war

1) Kaunitz an Ritter. Wien. 21. September 1777. Copia. Beilage zur Weisung des Staatskanzlers für Mercy v. 5. Januar 1778. H. H. u. St. A. Frankreich. Correspondenz 211.

2) Ritters Denkschrift vom 14. Januar 1778. Bayer. Geh. St. A. 
bisher nur wenig hervorgetreten und hatte an dem fortwährenden Ränkespiel innerhalb des Ministeriums keinen, wenigstens keinen nachweisbaren Anteil; er besass das Vertrauen des Kurfürsten und erfreute sich der Gunst des Wiener Hofes. Als ein glücklıcher Zufall ist es zu betrachten, dass der geschäftskundige Ritter gerade zur Hand war; von einer kurzen Reise an den zweibrück'schen Hof zurückkehrend erhielt er den Auftrag, gemeinsam mit Vieregg die hinterlassenen Papiere Beckers durchzusehen. Der kaiserliche Gesandte Freiherr von Lehrbach benützte jede Gelegenheit, Karl Theodor auf Ritter aufmerksam zu machen; man hatte in Wien schon längst den Plan gehabt, bei dem Abgang des mehr denn achtzigjährigen Beckers diesem Diplomaten die Leitung der auswärtigen Angelegenheiten zu verschaffen. Solange freilich die bayerische Erbfolgefrage ungelöst, der Gegenstand geheimer Unterhandlungen der beiden Höfe war, musste Ritter seinen Posten in Wien behalten; sobald aber die geplante Vereinbarung zu beiderseitiger Zufriedenheit getroffen war, stand Ritters Berufung an die Spitze der Geschäfte nichts melır im Wege.

Unmittelbar nach seiner Ernennung zeigte Vieregg durch eizen Secretär den in Mannheim residirenden Vertretern der fremden Mächte an, dass er bis auf Weiteres die Leitung der auswärtigen Angelegenheiten übernommen habe; Lehrbach, der abwesend war, benachrichtigte er schriftlich. Ueberall zeigte er grossen Eifer, aber der völlige Mangel an Geschäftskenntnis liess sich nur langsam überwinden; längere Zeit besorgte Ritter die Geschäfte und Vieregg gab uur den Namen her. Unter diesen Umständen stand es von vornherein fest, dass der Nachfolger Beckers keine Aenderung in der pfälzischen Politik herbeiführen werde; subald die ersten and grössten Schwierigkeiten überwunden waren, erhielt Ritter von dem Kurfürsten den Auftrag in einem Schreiben nach Wien die dort durch Beckers Tod etwa wachgerufenen Besorgnisse zu zerstreuen und zu erklären, dass die bayerische Angelegenheit in gutem Gange sei.

Gegen Ende des Monats November war Vieregg soweit eingear= beitet, dass Ritter an die Rückkehr auf seinen Posten denken kounte; am 29. unterzeichnete Karl Theodor die Vollmacht für ihn zu Verhandlungen mit den Beauftragten des Kaisers und der Kaiserin-Königin, sowie zum Abschluss einer Convention oder auch mehrerer Conventionen 1). Nach kurzem Aufenthalt in München traf Ritter, der, wie

1) Gedruckt in der ,Vollständigen Sammlung von Staatsschriften zum Behuf der bayerischen Geschichte etc. Bd. 3. S. 5 bis 7 . 
hier bemerkt werden mag, seit einem Jahre auch Bayern am Kaiserhof vertrat, am 13. Dezember in Wien ein.

Inzwischen war Lehrbach in das Geheimnis eingeweiht worden. Kaunitz hatte es für sehr wünschenswert gehalten, dass nach Ritters Abreise eine zuverlässige Persönlichkeit in Mannheim sei, die den Kurfürsten in seiner guten Gesinnung befestige und Intriguen der pfälzischen Partei vorbeuge; sein Antrag Lehrbach mit dieser Aufgabe zu betrauen hatte den Beifall Maria Theresias gefunden und am 23. November war aus der Staatskanzlei eine ausführliche Weisung an den Gesandten ergangen 1). Er erhielt dadurch Kenntnis von der Rechtsfrage, von den bisherigen Massnabmen und von dem augenblicklichen Stand der Dinge, sowie von den fernerhin noch erforderlichen Vorkehrungen. Zwei kurze Abhandlungen über die Rechte von Kaiser und Reich und über die Ansprüche des Erzhauses dienten zur Ergänzung der Instruction; rermutlich waren es dieselben, die Binder in März dem Freiherrn von Ritter übergeben hatte. Dieses inhaltreiche Schreiben war gerade noch so zeitig in Mannheim angekommen, dass Lehrbach wenigstens noch eine längere Unterredung mit Ritter haben konnte, bevor dieser sich auf den Weg machte.

Von dem Augenblick an, da Ritter wieder in Wien anlangt, eröffnet sich in den Berichten dieses Diplomaten eine Quelle von höchstem Wert fur die Geschichte des bayerischen Erbfolgestreites; wührend bis dahin die für die Vorgeschichte der pfälzisch-österreichischen Convention zweifellos hochwichtigen Depeschen des Gesandten von Wien nach Mannheim im Geheimen Staatsarchiv zu München nicht vorhanden zu sein scheinen, liegen sie von Mitte Dezember 1777 an ausnahmslos im Original vor; und überdies sind auch die Reskripte des Kurfürsten, sowie die Weisungen Viereggs an Ritter von da ab nahezu vollzählig erhalten.

Am 14. Dezember meldete Kaunitz der Kaiserin die erfolgte Ankunft des pfälzischen Gesandten und suchte eine Audienz für ihn nach; er fügte hinzu, nach Ritters Aeusserungen scheine der Mannheimer Hof zu einer Verständigung über die beiderseitigen Ansprüche bereit zu sein, doch dürften sich über die Art und den Inhalt derselben noch wichtige Anstände ergeben ${ }^{2}$ ). Huldvoll wurde Ritter am 16. von Maria Theresia, danach von dem Kaiser empfangen. In diesen Audienzen, sowie in den Besprechungen mit Kaunitz und Colloredo gewann er den

1) Kaunitz an Lehrbach. Wien 23. November 1777, Conzept. H. H. u. St. A., Staatskanzlei, Weisungen ins Reich 29.

2) Vortrag Kaunitz vom 14. Dezember 1777. H. H. u. St. A. 
Eindruck, dass man mit etwas Nachgiebigkeit hüben und drüben wohl zu einem beide Teile befriedigenden Ergebnis gelangen werde ${ }^{1}$ ).

Da traf am 19. die Nachricht ein, dass Kurfürst Maximilian Joseph von Bayern erkrankt sei und dass die Krankheit wohl als Kinderpocken sich entwickeln werde. Die Möglichkeit, ja Wahrscheinlichkeit einer unmitteibar bevorstehenden Eröffnung der bayerischen Erbschaft musste ins Auge gefasst werden. Ueberzeugt, dass die geplante Vereinbarung dus beste Mittel sei, einfach und rasch die Frage zu lösen, forderte der Staatskanzler nach eingeholter Erlaubnis den pfälzischeu Gesandten auf, sogleich von seinem Hofe sich die Ermächtigung zur Abtretung von Niederbayern und Mindelheim zu erbitten. War erst diese Cession vertragsmässig festgestellt, so konnte Kurpfalz bei eintretendem Todesfall in München von seinem Anteil Besitz ergreifen, während dies sonst der Kaiser zu thun hatte. Gleichzeitig erging an den kaiserlichen Gesandten in München, Grafen Hartig und an Borié in Regensburg der Befehl, von den geheimen Vollmachten zur Besitzergreifung Bayerns eintretenden Falls keinen Gebrauch zu machen ${ }^{2}$ ).

Ritter war beim Eintreffen der Münchner Nachrichten zuuächst nicht ohne Sorge gewesen, der Kaiser möge, vor die Entscheidung gestellt, doch den zwar gefahrvollen, aber im Falle des Erfolges lohnenden Weg der Einziehung Bayerns einschlagen. Auf seine Anfrage hatte er jedoch die beruhigende Versicherung erhalten, dass die kaiserlichen Najestäten nach wie vor zu einer freundschaftlichen Vereinbarung bereit seien, doch düriten pfälzischerseits keine den bisherigen mündlichen Verabredungen zuwiderlaufende Massregeln ergriffen werden. Einen Beweis tür die Aufrichtigkeit dieser Versicherung erhielt er alsbuld in Gestalt jener Aufforderung, sich eiligst die Ermächtigung zur Abtretung von Niederbayern und Mindelheim zu verschaffen; die Antwort, die er am 20. überreichte, enthielt die Bedingungen, unter denen Karl Theodor abschliessen wollte ${ }^{3}$ ). Der Kurfürst erkannte den Anspruch Oesterreichs auf Niederbayern nur für den sog. Straubingischen Teil des Herzogtums an, der 1426 nach dem Tod des Herzogs Johann, Grafen von Holland, von Kaiser Sigismund an Herzog Albrecht von Oesterreich verliehen, 1429 aber an die anderen niederbayerischen Herzöge gegeben worden war; er sprach die Erwartung aus, dass man ihm nichts Unbilliges zumuten werde. Wie nun somit in der Con-

1) Ritter an Vieregg. Wien, 17. Dezember 1777. Orig. Bayr. Geh. St. A.

2) Vortrag Kaunitz' vor Maria Theresia. 19. Dezember 1777. H. H. u. St. A.

s) Promemoria Ritters. Wien 19. Dezember 1777. Copia. Bayr. Geh. St. A. K. schw. $329 / 32$. 
vention der Anteil des Erzhauses an der bayerischen Erbschaft bestimmt angegeben wird, so verlangt Karl Theodor die Aufzählung aller Kurpfalz zustehenden Rechte und zufallenden Teile, und zwar entweder in der Convention selbst oder in bündigen Nebenerklärungen. Vor Allem will er das Erbrecht des pfülzischen Hauses auf Grund der Abstammung von dem ersten Erwerber ausdrücklich anerkannt wissen; dauach sollen einzeln als dem kurpfälzischen Erbteil zugehörig aufgeführt werden: Ganz Oberbayern; das nicht-Straubingische Niederbayern; die Neoaquisita und zwar sowohl Reichsleheu als Allodialgüter; die böhmisehen Lehen in der Oberpfalz sammt den dortigen Neuerwerbungen Leuchtenberg, Sulzburg und Pyrbaum. Der Wiener Hof muss sich ferner verpflichten an einer billigen Regelung der Allodialansprüche Dritter mit zu wirken; Kaiser und Reich haben allen weiteren Ansprüchen an Bayern zu entsagen. - $\mathrm{Da}$ alle diese Punkte bereits in der ersten Convention entschieden werden sollten, drängte Ritter auf schleunige Herbeiführung eines Einverständnisses darüber. Für die zweite Convention stellte er die Bereitwilligkeit des Kurfürsten in Aussicht, entweder einzelne Bezirke oder auch den ganzen Complex der ihm zufallenden bayerischen Erbschaft, nötigenfalls sogar einschliesslich der , in dortigen Gegenden liegenden Herzogtümer und Güter" auszutauschen "gegen andere annehmliche eigens zusammenhängende T'erritoria und Lande", die den Wert der abzutretenden Gebiete erreichen; er sprach den Wunsch aus, dass der Wiener Hof mit einem billigen Austauschvorschlag hervortrete. Gewissermassen einen Protest gegen das Verlangen, des Stautskauzlers, dass keine den mündlichen Verabredungen zuwiderlaufeuden Schritte geschähen, enthält der Schluss der Denkschrift, welcher die Unverbindlichkeit aller dieser vorläufigen Verhandlungen, so lange nicht ein bindender Abschluss erfolgt sei, für beide Höfe ausdrücklich zur Bedingung macht.

Ritter selbst war vollkommen davon überzeugt, dass nur durch eine uneingeschränkte Vollmacht zu sofortigem Abschluss unermesslichem Schaden vorgebeugt werden könne; ohne zu erwähnen, dass Kaunitz diesen Wunsch kuudgegeben habe, bat er in seinem Bericht an Vieregg ${ }^{1}$ ), man möge ihn von der in semer Instruction enthaltenen Verpflichtung, den Conventionsentwurf vor der Unterzeichnung nach Mannheim einzusenden, tür den Notfall befresen; auch möge der Kurfürst im Voraus die Genehmigung des von seinem Gesandten abge-

1) Ritter an Vieregg. Wien. 20. Dezember 1777, Orig. Bayr. Geh. St. A. 
schlossenen Vertrags, wie dieser auch lauten werde, zusichern. bir begründete dieses allerdings ganz ungewöhnliche Verlangen mit der ausserordentlichen Gefahr, welche durch eine Verzögerung herbeigeführt werden könne, wenn plötzlich der Kurfürst von Bayern sterbe oder wenn etwa unvorhergesehene Ereignisse an Wiener Hofe einträten, bevor der Vertrag unterzeichnet sei. - $\mathrm{Zu}$ diesen gefürchteten Ereignissen, deren Zeitpunkt sich nicht vorausbestimmen liess, gehörten, wie Ritter später einmal sagte, der Tod der Kaiserin, Colloredos oder Kaunitz'. - Nur der sofortige Abschluss könne, falls Maximilian Joseph jetzt sein Leben beschliesse, Kurpfalz davor bewahren, dass die Ansprüche von Kaiser und Reich und die des Erzhauses gemeinsam zur Geltung gebracht würden; nur so werde man die Intervention des Kaisers vermeiden und erreichen können, dass beide vertragschliessende Teile die ihnen zufallenden Gebıete ungehindert besetzen. Der Gesandte fügte noch die Mahnung hinzu, Karl Theodor möge sich auch nach dem Eintreffen der Todesnachricht aus München ruhig halten und keinen Schritt zur Besitzergreifung thun, bis die Convention abgeschlossen vorliege. Dafür glaubte er aber auch bei genauer Befolgung seiner Ratschläge den günstigsten Erfolg der Verhandlungen prophezeien zu dürfen: ganz Europa werde überrascht und erstaunt sein, wenn eine Frage, die einen allgemeinen Brand zu entzünden gedroht habe, in grösster Ruhe gelöst sei; unsterblichen Ruhm aber würden der Kurfürst und sein Minister davontragen.

Mit der Beantwortung der Ritter'schen Note beeilte sich Kaunitz trotz des gegebenen Versprechens nicht allzu sehr; wahrscheinlich hat er inzwischen den pfälzischen Einwand gegen die Ansprüche auf ganz Niederbayern einer Prüfung unterziehen lassen; erst am 26. Dezember hielt er der Kaiserin Vortrag darüber. Es war tür den Fortgang der Verhandlungen von grosser Wichtigkeit, dass der Staatskanzler, seine bisherıge Forderung einschränkend, sich nunmehr mit dem Straubingischen Anteil des Herzogtums Niederbayern begnügen wollte; damit war der bedeutendste Differenzpunkt beseitigt. Dagegen riet er der Kaiserin, die Neoaquisita nicht hinzugeben, sondern einstweilen ihre Verwendung für deren Neuverleihung bei Kaiser und Reich zu versprechen; die Frage der böhmischen Kronlehen, die dem pfälzischen Hause nur ex nova gratia verliehen werden könnten, sollte überhaupt erst bei der zweiten Convention erörtert werden, ebenso wie die Berichtigung der Allodialansprüche; über diese zweite Convention wollte er sich aber erst äussern, wenn die erste ins Reine gebracht sei.

Maria Theresia gab den Vorschlägen des bewährten Beraters ihre Zustimmung; es dauerte aber wieder drei Tage, bis Ritter in den 
Besitz der österreichischen Antwort kam ${ }^{1}$ ). Denn Kaunitz suchte ängstlich den Schein zu vermeiden, als ob sein Hof ein übergrosses Verlangen nach dem Abschluss trage. Freilich lauteten auch die Nachrichten "über das Befinden des bayerischen Kurfürsten günstig und mit der Besorgnis schwand der Anlass zur Eile. Die Antwort, ebenfalls als Promemoria bezeichnet, datirt vom 29. Dezember; sie bildet die Grundlage der Convention vom 3. Januar 1778.

Ritter, hocherfreut, dass die Beschränkung auf das Straubingische Gebiet zugestanden war, gab der Hoffnung Raum, dass einige Besprechungen mit den österreichischen Staatsmännern genügen würden, um auch die andern Punkte zur Zufriedenheit seines Herrn zu ordnen und völliges Einverständnis zu erreichen. Die Verzögerung durch das Neujahrsfest mit seinen Feierlichkeiten machte ihm keine Sorge; der Kurfürst von Bayern war, wie man allerwärts glaubte, wieder ausser Lebensgefahr ${ }^{2}$ ).

Aber die Dinge kamen anders, als man gedacht hatte. Am Neujahrstag um 5 Uhr Nachmittags traf in Wien die Nachricht ein, dass Kurfürst Maximilian Joseph am 30. Dezembər gestorben sei. Ritter, von Colloredo sogleich in Kenntnis gesetzt, geriet in die grösste Verlegenheit, denn in einer wenige Stunden vorher eingelaufenen Depesche Viereggs war ihm die erbetene Ermächtigung zum sofortigen Abschluss der Convention verweigert worden. Die günstigen Nachrichten aus München hatten wohl auch in Mannheim einen beruhigenden Einfluss ausgeübt, man hielt dort die Lage nicht mehr für kritisch, und der Minister wagte es nicht, dem Widerstreben des Kurfürsten gegen dıe Bevollmächtigung Ritters entgegenzutreten. Selbst für den schlimmsten Fall rechnete Karl Theodor auf die Loyalität der Kajserin-Königin und des Kaisers, die gewiss vor dem Eintreffen der pfälzischen Antwort auf den von dem Gesandten einzuschickenden Conventionsentwurf keine gewaltsamen Massregeln ergreifen würden ${ }^{3}$ ). Ritter eilte nach erhaltener Mitteilung sofort zu Colloredo und Kaunitz; er gab ihnen die Versicherung, dass sein Hof sich durch den Eintritt des gefürchteten

1) Promemoria an den Freiherrn von Ritter. Wien. 29. Dezember 1777. Copia. - Bayr. Geh. St. A.

2) Ritters Postskript zu Depesche Nr. 7 vom 1. Januar 1778, geschrieben am 31. Dezember 1777, wie aus den Worten: , le grand gala de demain . . .* hervorgebt.

3) Vieregg an Ritter. Mannheim. 27. Dezember 1777. Concept. Bayr. Ges. St. A. - K. schw. $320 / 32$. 
Ereignisses nicht in seinen seitherigen Absichten irre machen lassen, dass er auch sonst keinen Schritt thun werde, der nur im Entferntesten den Verdacht eines Gesinnungswechsels gestatte. Schwer genug mag $\mathrm{ihm}$ die $^{-}$von Vieregg anbefohlene Eröffnung geworden sein, dass Karl Theodor sich sofort nach Eintritt des Todesfalles nach Bayern begeben werde, allerdings nicht um förmlich von dem Herzogtum Besitz zu ergreifen, sondern um die Ordnung aufrechtzuerhalten und den Intriguen der in München erwarteten Kurfürstin-Witwe Maria Antonia ron Sachsen entgegenzutreten. Indes nahmen die Minister seine Mitteilungen freundlicher auf als er erwartet haben mochte; sie gaben ihm vertraulich zu verstehen, es liege nur an $\mathrm{ihm}$, durch unverzüglichen $\mathrm{Ab}$ schluss der Vereinbarung die Folgen des vertragslosen Zustandes zu vermeiden. Jetzt erst erfuhr der Gesandte, welches Schicksal über Bayern gekommen wäre, wenn nicht der pfälzische Hof sich so entgegenkommend gezeigt hätte; man erzählte ihm nicht ohne Absicht, dass nur durch seine Denkschrift vom 19. Dezember die einstweilige Suspendirung der dem kaiserlichen Gesandten in München und dem österreichischen Vertreter in Regensburg früher gegebenen Vollmachten zur Besitzergreifung des ganzen Herzogtums bewirkt worden sei; dagegen werde die Besitzergreifung des Straubingischen Gebietes für das Erzhaus ungesäumt erfolgen. Er sah sich vor die Alternative gestellt: Annahme oder Ablehnung der Convention; nahm or an, so konnte sein Herr alles nicht-Straubingische Gebiet, dazu die Lehen, Allodialgüter und Neoaquisita in Besitz nehmen, ohne, zunächst wenigstens, Widerspruch bei Kaiser und Reich oder bei der Kaiserin-Königin zu finden; - lehnte er ab, dann nahm der Wiener Hof den ursprünglichen Plan wieder auf, österreichische Truppen besetzten sofort im Namen des Kaisers die bayerischen Lande; Karl Theodor musste sich mit der Oberpfalz begnügen, die nach den Bestimmungen des Westpfälischen Friedens an Kurpfalz zu fallen hatte. Wenn Ritter noch schwankte, welche Wahl er treffen sollte, so wurden auch seine letzten Bedenken verscheucht durch die Erklärung der kaiserlichen Minister, dass man, wenn Karl Theodor die Convention abschliesse, nicht nur nichts gegen seine Reise einzuwenden habe, sondern seinen Aufenthalt in München sogar gern sehe; Maria Theresia werde ihn dann bei der Besitzergreifung unterstützen and Fürsprache beim Kaiser einlegen, dass er dasselbe thue; - denn gerade die Nichtbefolgung des Rats, keine eigenmächtigen Schritte zu thun, hatte in ihm die grösste Besorgnis wachgerufen. So entschloss er sich denn auf eigene Verantwortung zu handeln und, dem Drängen des Wiener Hofes nachgebend, die Convention abzuschliessen; nur bedang er sich aus, dass 
zu ihrer Gültigkeit die Ratification des Kurfürsten erforderlich sein solle ${ }^{1}$ ).

In diesem Entschluss konnte ihn die Aufregung nur bestärken, die sich der Wiener Hofkreise beim Eintreffen der Nachricht bemächtigte, der Kurfürst von der Pfalz habe sogleich nach dem Tode Maximilian Josephs durch ein Patent Besitz von ganz Bayern ergriffen. Man kannte den Zusammenhang der Dinge nicht, man wusste nicht, dass das Patent ohne Auftrag Karl Theodors von der bayerischen Landesregierung auf Grund des pfälzisch-bayerischen Familienvertrags von 1774 erlassen worden war: man beschuldigte begreiflicherweise den pfälzischen Hof der Hinterhaltigkeit, ja fast des Wortbruchs. Die Verstimmung machte sich auch in den Verhandlungen bemerkbar: als Ritter an dem von Kaunitz ihm vorgelegten Conventionsentwurf einige Abänderungen vorgenommen wissen wollte, erklärte man ihm, das sei nicht mehr zulässig, nach den Vorgängen in München müsse der Vertrag wie er sei auf der Stelle unterzeichnet werden ${ }^{2}$ ).

So blieb denn kein Ausweg übrig: am 3. Januar 1778 setzte Ritter seinen Namen unter die Conventionsurkunde; ein Courier machte sich sofort auf den Weg, um die Genehmigung des Kurfürsten einzuholen. Man zweifelte in Wien gar nicht an der alsbaldigen Ratification und Kaunitz sprach dem pfälzischen Gesandten sofort nach der Unterzeichnung im Auftrag des Kaisers die Erwartung aus, dass der Kurfürst den bayerischen Behörden das bescheidenste und entgegenkommendste Betragen gegen die einrückenden österreichischen Truppen zur Pflicht mache und von dieser Verfügung den Befehlshaber des Occupationskorps, Feldmarschall-Lieutenant Baron von Langlois in Linz in Kenntnis setze.

Die zwischen Kaunitz und Ritter vereinbarte Convention vom 3. Januar 1778 beraubte Karl Theodor eines wohlhabenden und stark bevölkerten Gebietes, sicherte ihm dagegen den ungeschmälerten Besitz des grösseren Restes von Bajern für die Zukunft dadurch, dass das Erzhaus allen weiteren Ansprüchen ausdrücklich entsagte und das pfälzische Erbrecht anerkannte. Auch die Herrschaft Mindelheim fiel un Oesterreich, das darauf eine alte Anwartschaft geltend machen konnte. Die Neuverleihung der beträchtlichen böhmischen Kronlehen in der Oberpfalz wurde Karl Theodor in Aussicht gestellt, ja sogar ihm Hoffnung auf Ueberlassung des Oberhoheitsrechtes gemacht, dagegen unterblieb die Erwähnung der von der wilhelminischen Linie

1) Ritter an Vieregg. Wien. 1. Januar 1778. Orig. Bayr. Geh. St. A.

2) Ritters Denkschrift vom 14. Januar 1778. 
in Bayern neuerworbenen Reichslehen. Damit jedoch über diesen letzten Punkt keine Missverständnisse einträten, gab Colloredo im Namen des Kaisers den Rat, der Kurfürst möge keine eigenmächtigen Schritte thun und die nach geschehener Ratification erfolgende Willensäusserung des Kaisers abwarten 1).

Waren diese Bestimmungen, die Hoffnungen erweckten ohne Gewähr für ihre Erfüllung zu bieten, schon geeignet Anlass zu Missverständnissen zu geben, so galt dies noch viel mehr von der Bestimmung, dass über die genaue Abgrenzung des ehemals straubingischen Gebietes die von $\mathrm{pfälzischer}$ Seite aus den bayerischen Archiven vorzulegenden urkundlichen Beweise entscheiden sollten. Ritter mag wohl geglaubt haben, es solle dadurch die Beeinträchtigung eines Teils durch den andern verhütet werden, - wo sollten die erforderlichen Beweisurkunden anders sein als in den bayerischen Archiven? - auf österreichischer Seite hat aber bei dieser Forderung doch wohl, wie der Verlauf der Occupation zeigt, das Bestreben mitgewirkt von dem preisgegebenen Teil Niederbayerns das eine oder andere Rentamt mit einzuziehen in der richtigen Voraussetzung, dass der verlangte Beweis für die Zugehörigkeit zum nicht-Straubingischen Gebiet schwer zu führen sein werde. Je mehr Bezirke aber der Wiener Hof besetzen liess, um so mehr Tauschobjecte bekam er in die Hand für die zweite Convention.

Die weitere Entwicklung der Dinge hing nun davon ab, ob Karl Theodor den Vertrag annahm oder verwarf. Bis zur Entscheidung hierüber, die innerhalb vierzehn Tagen nach erfolgter Unterzeichnung der Convention fallen musste, versehob Maria Theresia auch den Einmarsch ihrer Truppen in das ihr zufallende Gebiet; sie that dies aus Rücksicht auf des Kurfürsten bekannte Empfindlichkeit in allen Dingen, die seine wirkliche oder vermeintliche Würde berührten. Selbst der optimistische Ritter hielt es für ratsamer, eine vielleicht überflüssige Note zu übergeben, als auch nur die kleinste Vorsicht ausser Acht zu lassen: am 4. Januar legte er in einem Promemoria dar, dass sich die österreichische Anerkennung des pfälzischen Besitzstandes selbstrerständlich auch auf die dem Sulzbach'schen Hause bereits gehörigen Gebiete erstrecke, und bat mit Rücksicht auf die zerstreute Lage dieser Besitzungen um ganz besondere Aufmerksamkeit seitens des kaiserlichköniglichen Kommissars und der ihn begleitenden Truppen ${ }^{2}$ ).

1) Ritter an den Kurfürsten. Wien. 4. Januar 1778. Orig. Bayr. Geh. St. A, - K. schw. $329 / 32$.

2) Orig. H. H. u. St, A. - St. K. Bayern 49 . 
Am 6. Januar traf der Courier mit Ritters Depeschen und der Convention in München ein. Karl Theodor war auf die Todesnachricht hin noch in der Neujahrsnacht, beg]eitet von Vieregg, von Mannheim abgereist und an 2. Januar Vormittags in der bayerischen Hauptstadt angelangt ${ }^{1}$ ). Die Mitteilung, mit welcher der pfälzische Legationssekretär von Hammerer ihn hier empfieng, überraschte ihn peinlich; er mochte sich aber doch wohl erinnern, dass er gelegentlich der Beratungen über den bayerisch-pfälzischen Familienvertrag im Jahre 1774 ein Patent eigenhändig unterschrieben hatte, welches bei Maximilian Josephs Tod sofort veröffentlicht werden sollte, um zu verhindern, dass eine dritte Partei sich in den Besitz der Erbschaft setze. Jetzt freilich konnte diese Voreiligkeit, wie Karl Theodor das völlig korrekte Verfahren des bayerischen Ministeriums nannte, die bedenklichsten Folgen nach sich ziehen. Deshalb beauftragte er Vieregg, dem Gesandten in Wien ausdrücklich die Versicherung zu geben, dass der Entschluss zu einer Vereinbarung mit dem Kaiserhof unerschütterlich feststehe; man möge den Vorgängen in München, an denen er keinen Teil habe, keine Bedeutung beilegen. Bemerkt zu werden verdient hierbei, dass Vieregg um diese Zeit von dem wirklichen $\mathrm{Zu}$ sammenhang der Besitzergreifung noch nicht unterrichtet war: er glaubte, sie sei auf Grund einer alten Vollmacht für Hammerer erfolgt, die man um Aufsehen zu vermeiden und das Geheimnis der Unterhandlung zu wahren, nicht widerrufen habe ${ }^{2}$ ). Karl Theodor hatte also noch keine Zeit - oder vielleicht nicht den Mut? - gefunden, seinen leitenden Staatsmann in das Geheimnis der Abmachungen von 1774 einzuweihen.

Ein grosser Trost war für den Kurfürsten die Ankunft des Freiherrn von Lehrbach; der kaiserliche Gesandte, der auf seiner DeutschOrdens-Kommende Ellingen den ihm bewilligten Urlaub verbrachte, hatte sich auf die Kunde von Maximilian Josephs Tod sofort nach München auf den Weg gemacht; er wurde am 3. Januar in Audienz empfangen. Als er dabei auf das Besitzergreifungspatent und die darin angeführten Hausverträge von 1766, 1771 und 74, deren Existenz seinem Hofe gänzlich unbekannt sei, zu sprechen kam, geriet Karl Theodor in grosse Verlegenheit und sprach sein Bedanern aus, dass seine eilige Herreise die Publication des Patentes nicht habe verhin-

1) Der Direktor der Staatskanzlei Geh. Rat von Stengel und der greise Freiherr von Zedtwitz folgten unmittelbar danach. Unger, kursächs. Resident, an Stutterheim. München 4. Januar 1778. Conzept. Dresdener Archiv. Loc. 3463 Dépêches écrites en cour 1778.

2) Vieregg an Ritter. München. 3. Januar 1778. Conzept. Bayr. Geh. St. A 
dern können. Das Vorhandensein der Hausverträge suchte er mit den sächsischen Ansprüchen an das bayerische Allodium zu rechtfertigen; sie hätten dem Kaiser zur Bestätigung vorgelegt werden sollen. Schliesslich beteuerte er, dass keine Gesinnungsänderung stattgefunden habe noch auch stattfinden werde, und ersuchte den Gesandten, darüber an seinen Hof zu berichten.

Wenige Stunden nach Eingang der Wiener Depeschen begab sich Lehrbach - am 6. Janıar - zu dem Kurfürsten. Dieser hatte bereits mit dem bisherigen Leiter der bayerischen Politik, dem Obersthofmeister Grafen Seinsheim und dem bayerischen Geheimen Kanzler Freiherrn von Kreittmayr das Vertragsinstrument einer Durchsicht unterzogen, da der hierzu seiner Stellung nach berufene Freiherr von Vieregg mit den speciell bayerischen Verhältnissen gar nicht bekannt war. Er verhehlte Lehrbach nicht, dass der Inhalt der Convention ihn in arge Verlegenheit setze; das abzutrennende Gebiet erstrecke sich vielfach weit in sein Land hinein; statt dass man allen Anlass zu Streitigkeiten für die Zukunft beseitige, schaffe man so eine Fülle neuer Streitpunkte. Auch könne er den Vertrag nicht sofort, wie man es von ihm verlange, unterzeichnen, da dies auf die gerade versammelten Landstände des Herzogtums den ungünstigsten Eindruck machen werde. Indes versprach er sich die Frage reiflich zu überlegen, die einschlägigen Akten beibringen zu lassen und dann seine Antwort zu erteilen. Am Abend des 6. fand eine lange Beratung über die durch den Abschluss geschaffene politische Lage statt, an der ausser dem Kurfürsten, Vieregg und den beiden bereits eingeweihten bayerischen Ministern auf Lehrbachs Empfehlung der Geheime Archivarius Graf Zech theilnahm. Es wurde, einem Vorschlag Kreittmayrs folgend, beschlossen, dem Kaiserhof die Oberpfalz, Neuburg und die bayerischen Ansprüche auf einige in nürnbergischem Besitz befindliche Aemter anzubieten, um durch diese Abtretungen das Herzogtum Bayern ungeteilt zu erhalten. Als Lehrbach am folgenden Vormittag bei Seinsheim, der ihn um eine Unterredung gebeten hatte, erschien, erhielt er den Bescheid, der Kurfürst wolle vorläufig abwarten, ob der Wiener Hof sich nicht zur Annahme eines anderen, für ihn günstiger gelegenen Landstrichs und zum baldigen definitiven Abschluss mit Verzicht auf spätere Austauschungen bereit finden lasse. Seinsheim und der gleichfalls anwesende Kreittmayr betonten die notwendige Rücksicht auf die Landstände und baten den Gesandten, er möge auf eine Herabminderung der Ansprïche seines Hofes hinwirken ${ }^{1}$ ).

1) Lehrbach an Kaunitz, München. 9. Januar 1778. Orig. H. H. u. St. A. St, K. Bayern 49 , 
Eine Depesche Viereggs setzte Ritter von den Conferenzbeschlüssen in Kenntnis; ein Reskript des Kurfürsten befahl dem Gesandten darauf zu dringen, dass man nicht mit bewaffneter Hand an so schwierige Fragen herantrete, sondern sich vielmehr zur Annahme eines passenden Aequivalentes verstehe ${ }^{1}$ ). Beide Schreiben gingen jedoch, da Lehrbach die Absendung des Couriers verzögerte, erst am 9. Januar ab.

Ritter sah inzwischen ungeduldig der Antwort aus München entgegen. Die am 5. einlaufende Depesche Viereggs gab ihm neuen Mut, sie erklärte ihm das bis dahin gänzlich unbegreifliche Besitzergreifungspatent wenigstens einigermassen, wenngleich er peinlich berührt wurde durch die Bemerkung, dass die bayerische Landesregierung es nicht für notwendig gehalten hatte, ihn in seiner Eigenschaft als bayerischer Gesandter von einem so bedeutungsvollen Schritt in Kenntnis zu setzen. Die bereits eingetretenen Folgen der Nachricht waren freilich nicht mehr rückgängig zu machen, doch liessen sich wenigstens weitere nachteilige Massregeln durch schleunige Klarstellung des Sachverhalts verhindern. Am 2. Januar schon hatte der Kaiser sieben Bataillone und das Dragoner-Regiment Prinz Coburg zum Einmarsch in Bayern bestimmt, dem F.-M.-L. Baron von Langlois die Leitung des Onternehmens übertragen und Tags darauf ihm eine Instruction sowie den Befehl erteilt, das bayerische Gebiet bis zur Linie Haag-Waldmünchen zu besetzen, das Hauptquartier nach Straubing zu legen ${ }^{2}$ ). Die Nachricht von der thatsächlichen Besitzergreifung ganz Bayerns durch das Patent vom 30. Dezember hatte alsdann Anlass zu einer beträchtlichen Verstärkung des Occupationskorps gegeben; man hatte ausserdem dem Gesandten erklärt, wenn die Ratification verweigert werde, werde der Kaiser sofort ganz Bayern einziehen und den Kurfürsten wegjagen. Noch am Abend des 5. begab sich Ritter zu den kaiserlichen Ministern und teilte ihnen den Zusammenhang der pfälzischen Besitzergreifung mit; am folgenden Tage hatte er Gelegenheit, bei der Notification des Regierungsantritts Karl Theodors den Kaiser gegenüber das unerschütterliche Festhalten seines Hofes an der hisherigen Politik zu beteuern ${ }^{3}$ ). Seine Versicherungen blieben nicht ohne Wirkung, aber bald begann man sich zu wundern, dass noch immer keine Antwort aus München anlangte, während sich allerlei Gerüchte verbreiteten, die auf die Absicht bewaffneten Widerstandes

1) Vieregg an Ritter. München. 8. Januar. Conzept. Bayr, Geh. St. A. Karl Theodor an Ritter, von demselben Datum, gedr. Arneth, Maria Theresia. Bd. 10, S. $797 / 8$.

2) K. K. Kriegs-Archiv. 1778. Cab.-A.

9) Ritter an Vieregg. Wien, 10. und 11, Jannar 1778, Orig. Bayr. Geh. St. A. 
der pfülzischen bezw. bayerischen Regierung schliessen liessen. In der Audienz, die Ritter am 11. Januar bei der Kaiserin zur Uebergabe des Notificationsschreibens hatte, gab Maria Theresia ihr Missvergnügen offen kund und drohte mit folgenschweren Repressalien, wenn jene Gerüchte sich bewahrheiteten und die Convention verworfen würde; dagegen stellte sie die freundschaftlichste Unterstützung des Kurfürsten in Aussicht für den nach Ratification des ersten zu schliessenden zweiten Vertrag. Diese Austauschconvention in Angriff zu nehmen erklärten sich jetzt auch die Minister bereit, die bisher nur geringen Eifer dafür gezeigt hatten. Aber auch sie konnten dem Gesandten ihre Ungeduld, ihre Besorgnis nicht verhehlen, denn von Lehrbach fehlte ebenfalls jede Nachricht über die Aufnahme des Vertrags vom 3. Januar. Der Gedanke lag nahe, dass die bayerische Partei, in deren Mitte der schwache Kurfürst mit seinem unerfahrenen pfälzischen Ratgeber sich befand, sich sei es aus böser Absicht, sei es um ihres Sondervorteiles willen der Vereinbarung widersetzte, und man traf ja mit dieser Vermutung ziemlich das Richtige. Auch Ritter dachte wohl, dass die bayerischen Minister ihre Hand im Spiel hätten; nicht ohne Grund hatte er vor ihnen gewarnt, aber er musste sich fragen, auf wessen Hülfe man rechnete, wie man überhaupt in München sich die weitere Entwicklung der Dinge vorstellen mochte. Von Frankreich war doch nichts zu erwarten, Breteuil, durch Kaunitz von den Inhalt der Convention in Kenntnis gesetzt, meinte, Kurpfalz habe gar nichts Besseres zur Erhaltung der Ruhe in Deutschland thun können. Aber selbst wenn der Versailler Hof anders dachte, so würde Bayern gewiss seinen Beistand teuer bezahlen nuüssen: die wieder ins Leben gerufenen Ansprüche des Hauses Orleans würden dann zu denjenigen Oesterreichs und Sachsens noch hinzutreten. Eher konnte man auf Preussens König zählen; aber welchen Preis hätte man diesem durch seinen politischen Egoismus bekannten Fürsten erst zahlen müssen!

Alle diese Erwägungen der Kaiserin und der Minister sowie die Ergebnisse seines eigenen Nachdenkens legte Ritter nieder in einer Depesche an Vieregg vom 11. Januar. Noch aber war der Courier nicht abgegangen, als das kurfürstliche Reskript und des Ministers Weisungen rom 8. und 9. in Wien eintrafen. Auf der Stelle fügte er der Depesche eine Nachschrift bei. Gegenüber der Klage, dass die Convention eine Zerreissung Bayerns bedeute, stellt er die Behauptung auf, die österreichische Besitzergreifung des straubingischen Anteils sei vorübergehend, reine Förmlichkeit und habe nur den Zweck dem Publikum Sand in die Augen zu streuen; die Regelung des Besitzstandes sei überhaupt der zweiten Convention vorbehalten. Dringend 
mahnt er, dass der Kurfürst an Stelle des bayerischen Ministeriums seinen eigenen Ruhm und seine Würde zu Rate ziehe und entschlossen Partei ergreife, - sonst sei Alles verloren; auch so schon werde die Einbusse an Vertrauen kaum mehr wieder gut zu machen sein. Wenigstens hätte man ihm, meint er, die Ratification zuschicken sollen für den Vertrag, wie ihn der Kurfürst vorschlage, wenngleich man sich mit diesen Vorschlägen ganz von dem bisher verfolgten Weg der Unterhandlung entferne; da hätte der Wiener Hof wenigstens nirht an der Absicht einer Verständigung zweifeln können, wie er es jetzt, nicht mit Unrecht, thue.

Man erkennt beim Lesen dieser Behauptungen den Diplomaten nicht wieder, der sich selbst einer dreissigjährigen Erfahrung rühmt. Unmöglich kann Ritter geglaubt haben, Oesterreich werde das rechte Innufer wieder fahren lassen; seit Jahren wusste Jedermann, dass der Wiener Hof den Besitz dieses wichtigen Stromlaufs anstrebe. Und weiter, war es denkbar, dass man in Wien in der bestimmten Weigerung bayerisches Gebiet abzutreten etwas anders als eine verblümte Verwerfung des Vertrags gesehen hätte? Das Bedenklichste aber war, dass seine Aeusserungen in München eine ganz falsche Auffassung wachrufen mussten, die der Sache des pfälzischen Hofes schwerlich von Nutzen sein konnte.

Am folgenden Tag, den 12. Januar, übergab Ritter den kaiserlichen Ministern das Reskript des Kurfürsten in Abschrift - auch Lehrbach hatte in München eine Abschrift erhalten; - in einer Begleitnote empfahl er dessen Inhalt den Majestäten zur Beherzigung 1). In höchster Ungeduld, schwankend zwischen Furcht und Hoffnung suchte er zu erkunden, wie wohl die Antwort lauten möge; doch die vertraulichen Mitteilungen, die man ihm machte, gaben keine Hoffinung, und der mündliche Bescheid, den Kaunitz ihm Abends erteilte, rechtfertigte selbst die schlimmsten Befürchtungen. In Allerhöchstem Auftrag erklärte ihm der Staatskanzler, dass der Kaiser und die Kaiserin entrüstet seien über die Verzögerung der Ratification und über die neuen Vorschläge; auch er persönlich in seiner Eigenschaft als Minister. der jederzeit aufrichtig und vertrauensvoll die Unterhandlung geführt, habe Grund sich gekränkt zu fühlen. Er liess durchblicken, dass er in den neuen Vorschlägen nur ein Mittel sehe Zeit zu gewinnen, damit das pfälzische Regiment in dem besetzten Gebiet festen Fuss fassen und zugleich erfahren könne, wie die fremden Höfe über die

1) Promemoria Ritters. Wien 12. Januar 1778. Orig. H. H. u. St. A. St. K. Bayern 49. 
Frage dächten, - wenn nicht sogar die Absicht vorliege, mit diesen zum Nachteil Oesterreichs Verabredungen zu treffen. Aber der Kaiserhof wolle sich nicht vor ganz Europa lächerlich machen lassen; Lehrbach werde sofort angewiesen, den Kurfürsten vor die Alternative zu stellen: Annahme der Convention wie sie ist - oder Ablehnung. Er fügte noch hinzu, die Verwerfung sei unter den gegenwärtigen Umständen für Oesterreich vorteilhafter als die Annahme, denn Alles stehe zu sofortiger Besitzergreifung bereit, die Patente seien gedruckt, die Truppen an der Grenze marschfertig; und komme es nun wirklich zum Einmarsch, so werde man auch vor den Thoren Münchens nicht Halt machen.

Ritter sah sein Werk, die Convention vom 3. Januar, auf deren Abschluss er bisher mit stolzer Befriedigung geblickt hatte, aufs Ernstlichste gefährdet, und doch konnte er kaum etwas zu ihrer Erhaltung thun. Es galt zunächst nur Zeit zu gewinnen, denn der Kurfürst hatte ja ausdrücklich erklärt die Convention annehmen zu wollen, wenn es unbedingt nötig sei. Deshalb beantragte Ritter, die KaiserinKönigin möge den Einmarsch noch einige Tage aufschieben; man erwiderte ihm aber, das sei nicht mehr möglich; nur soviel wurde zugestanden, dass die einrückenden Truppen noch nicht als Reichstruppen auftreten sollten. Die Veröffentlichung der Manifeste versprach Kaunitz noch sechs bis sieben Tage aufzuschieben, damit ein Courier von Ritter nach München abgehen und von dort mit der Entscheidung wieder zurückkehren könne. Aber die Vorlage eines anderen Vertragsentwurfs, über den man sich verständigen könne, schlug er ab mit der Bemerkung, sein Hof habe weitere Vorschläge nicht zu machen.

Tief erschüttert berichtete Ritter dies Alles an Vieregg, er mahnte, keinen Augenblick zu verlieren, da die gewährte Frist zweifellos nicht verlängert werde. Aber er zog auch für seine Person die Consequenzen aus der ihm unbegreiflichen Haltung seines Herrn, der den parteiischen Münchener Ratgebern mehr Vertrauen zu schenken schien, als dem langjährigen erprobten Vertreter am Kaiserhof: er bat, man möge die kurfürstliche Entschliessung durch eine mit annehmbaren Vorschlägen und mit Vollmachten zur Unterhandlung und zum Abschluss versehene Vertrauensperson nach Wien senden; er selbst sei zu mutlos und eingeschüchtert, um die Verantwortung noch länger auf sich zu nehmen ${ }^{1}$ ).

Kaunitz hatte kaum, wie man etwa glauben könnte, übertrieben, als er Ritter sagte, auch die Besitzergreifungspatente für das ganze

1) Ritter an Vieregg. Wien. 12. Januar 1778, Orig. Bạr. Geh. St. A. 
bayerische Land seien schon in Bereitschaft; am 12. Januar, da der Staatskanzler jene Mitteilung machte, befahl Kaiser Joseph dem Reichsvizekanzler ${ }^{1}$ ), alle Instructionen und Patente anzufertigen, die zur Besitzergreifung Bayerns im Namen des Reichs bis zur Ausgleichung aller strittigen Ansprïche auf die Succession erforderlich seien; am 14. sollten sie durch einen Courier befördert werden.

In München hoffte man wirklich, dass der Wiener Hof die neuen Vorschläge annehmen und sich mit den angebotenen oberpfälzischen Gebietsteilen begnügen werde. In dieser Stimmung traf Karl Theodor die Meldung des Rentamts Straubing, der Einmarsch der kaiserlichen Truppen stehe unmittelbar bevor; sie erregte die grösste Bestürzung; der Kurfürst liess Lehrbach rufen und bat ihn um seine Vermittlung, damit der Kaiser diesen Schritt doch wenigstens noch kurze Zeit aufschiebe; das Land werde sonst in die grösste Notlage geraten, er selbst aber, der Kurfürst, werde die von den Landständen geforderten Geldbewilligungen nicht erhalten ${ }^{2}$ ). An Ritter erging eine eilige Weisung, von dem Kaiserhof noch die Erfüllung dieses kleinen Wunsches zu verlangen und dabei immer wieder die reinen Absichten der pfälzischen Regierung hervorzuheben ${ }^{3}$ ). Als einen neuen Grund für den Aufschub der geplanten Besetzung sollte er die Besorgnis anführen, der König von Preussen werde in ihr einen Gewaltakt erblicken und die Gelegenheit wahrnehmen, um Kurpfalz in Jülich-Berg einen Streich zu spielen, überzeugt, dass der Wiener Hof nichts dagegen sagen werde.

Die Depeschen Ritters vom 10., 11. und 12. Januar zerstörten nun aber rasch alle Illusionen, denen man sich hingegehen hatte. Karl Theodor war schmerzlich betroffen, dass alle seine Vorstellungen gegen den Truppeneinmarsch vergeblich gewesen waren, besonders aber durch die Bemerkung, dass man ibu allen Ernstes im Verdacht feindseliger Gesinnung und schlimmer Absichten gegen die kaiserlichen Majestäten gehabt habe. Man darf es dem schwachen Fürsten wohl glauben, dass er nicht im Entferntesten an Widerstand gegen Oesterreich oder an die Einmischung einer fremden Macht gedacht hat. Zum Beweis seiner stets gleich gebliebenen Gesinnung hinsichtlich der bayerischen Erbfolge that er den entscheidenden Schritt: am 14. Januar setzte er seinen Namen unter die von Ritter geschlossene Convention.

1) Joseph an Colloredo. Wien. 12. Januar 1778. Orig. H. H. u. St. A. Bavarica 49.

2) Lehrbach an Kaunitz. München. 12. Januar 1778. Orig. H. H. u. St. A.

9) Vieregg an Ritter. München. 12. Januar 1778. Conzept. Bayr. Geh. St. A. 
Es ist Karl Theodor gewiss nicht leicht gewesen, den schönsten und fruchtbarsten Teil des ihm nach Maximilian Josephs Tod zugegefallenen Herzogtums abzutreten; er selbst sagt in dem Rescript an Ritter, dass er um der Ruhe Deutschlands und Europas willen den Vertrag mit gänzlicher Aufopferung seines Interesses ratificirt habe. Dafür hegte er aber auch die Hoffnung, dass der Kaiser und die Kaiserin-Königin nun ihre Versprechungen erfüllen und sich bei der zweiten Convention für die gebrachten Opfer erkenntlich erweisen würden ${ }^{1}$.

Der Kurfürst und sein Minister erwarteten, dass die Annahme der Convention genügen werde, den in Wien entstandenen Argwohn gänzlich zu zerstören, sie glaubten nunmehr Alles gethan zu baben, um die Reinheit ihrer Absichten darzuthun; in ihren eigenen Herzen aber lebte noch lange eine gewisse Bitterkeit fort, wie sie die Entrüstung über einen so ungerechten Verdacht wachgerufen hatte. Besonders Vieregg gab diesem Gefühl sowohl Lehrbach als Ritter gegenüber ungescheut Ausdruck. Wenn seinen in der Erregung niedergeschriebenen Zeilen Glauben geschenlt werden darf, so war er bereits seines Amtes überdrüssig, da er bemerken musste, wie seine Politık der Ehrlichkeit und Aufrichtigkeit eine Wirkung hatte, die der im Interesse seines Herrn gewünschten gerade entgegengesetzt war. Bei alledem war man aber ängstlich besorgt, dem Kaiserhof keinen Anlass zu begründeten Klagen zu geben. Da die Anerkennung Karl Theodors als Inhaber des Herzogtums Bayern auf dem Reichstag noch nicht erfolgt war - sie hieng ja, wenigstens nach österreichisclser Auffassung, von der Aunahme der Convention ab - unterliess man die Beisetzung jeglichen Titels in der Ratificationsformel. Man beeilte sich Aufklïrung zu geben über die so sehr beargwöhnte Sendung von Courieren nach Paris und Berlin: sie hatten die Notification von Karl Theodors Regieruugsantritt dorthin getragen; man suchte Ritter und durch ihn den Staatskanzler zu beruhigen über den Anteil einzelner dem Wiener Hofe nicht völlig genehmer Personen an den politischen Geschäften.

Während Vieregg für seine Person Ueberdruss an der Leitung der Geschäfte kundgibt, mahnt er mit eindringlichen Worten Ritter zu tapferem Ausharren auf seinem schwierigen Posten. Er versichert ihn des uneingeschränkt fortdauernden Vertrauens seines Herrn, er spricht ihm in dessen Namen sein Bedauern aus über die Unannehm-

1) Karl Theodor an Ritter. München. 14. Januar 1778. Conzept. Bayr. Geh. St. A, 
lichkeiten, denen er unter den herrschenden Verhältnissen ausgesetzt sei, und sucht seinen Mui wieder aufzurichten durch die Aussicht, dass auch der Wiener Hof ihm in kürzester Frist das alte Vertrauen bezeigen werde.

Mit der ratificirten Conventionsurkunde, die in Wien gegen das von Maria Theresia unterzeichnete zweite Exemplar ausgetauscht werden sollte, mit den Weisungen für Ritter und mit zwei kurfürstlichen Schreiben an die Kaiserin und an den Kaiser versehen, verliess noch am 14. Januar der Courier die bayerische Hauptstadt. Wenn er seine Reise auch noch so sehr beschleunigte: vor dem 16. Nachmittags, also vor Ablauf von zweimal vierundzwanzig Stunden konnte er nicht in Wien eintreffen. Mit bleierner Langsamkeit schlichen diese Stunden für Ritter dahin. Offenbar suchte er durch Schreiben seiner inneren Unruhe Herr zu werden. Vom 14. Januar ist datirt die „Gründliche Geschichtserzehlung und daraus erhellende Rechtfertigung des Betragens des Freyherrn von Ritter, in der Behandlung über die Bayerische Erbfolge mit dem K. K. Hofe", die er an Vieregg sandte. An diesem Tage erhielt er die Weisung vom 12. wegen des bevorstehenden Einmarschs kaiserlicher Truppen in Bayern; er machte die anbefohlenen Vorstellungen, doch ohne Erfolg. Dabei musste er wieder die schlimmsten Anschuldigungen seines Hofes anhören, ohne ihuen mit voller Ueberzeugung entgegentreten zu können, glaubte er doch selbst bereits, dass Karl Theodor ein anderes politisches System angenommen habe. Die Verweigerung der Ratification im kritischsten Augenblick erschien ihm als ein untrügliches Zeichen dafür, dass die bisherige Politik der Verständigung mit dem Kaiserhof aufgegeben sei. Nur die bayerischen Staatsmänner konnten diesen Umschwung bewirkt haben, sie, die von all dem Vorhergegangenen nichts wussten; zu ihrer Belehrung hatte er die Denkschrift vom 14. Januar bestimmt, vorausgesetzt, dass sie sich überhaupt belehren lassen wollten. Denn er mochte wohl selbst einigen Zweifel an dem Erfolg hegen, nachdem Kaunitz ihm seinen Verdacht mitgeteilt hatte, dass eine förmliche Verschwörung zwichen dem jüngst verstorbenen Beckers und dem Baron Zedtwitz auf pfälzischer, dem Ministerium in München auf bayerischer Seite bestanden habe bezw. noch bestehe, von der wahrscheinlich Vieregg gar nichts wisse, die möglicher Weise sogar dem Kurfürsten unbekannt geblieben sei. Zugleich aber wollte er durch die „Gründliche Geschichtserzehlung" sein Verhalten in der bayerischen Successionsverhandlung klarstellen und rechtfertigen gegenüber den Männern des neuen Systems, denen er zu weichen entschlossen war. Er erbat sich als Nachfolger auf seinem augenblicklich so wichtigen Posten 
einen Mann, der vollständig eingeweiht sei in die Grundsätze der nunmehr zu befolgenden Staatsweisheit, für sich selbst einen ehrenvollen Ruhestand ${ }^{1}$ ).

Endlich am 16. Januar schlug ihm die Erlösungsstunde. In aller Frühe hatte er noch einem Bericht an Vieregg verfasst über den stets wachsenden Verdacht gegen Karl Theodor, der durch das zweideutige Auftreten des Geheimen Staatsrats von Cuntzmann in Mannheim bis zu einem gewissen Grad gerechtfertigt werde, da erhielt er aus der Staatskanzlei die Nachricht, ein Courier Lehrbachs habe das bevorstehende Eintreffen der Ratification gemeldet; zugleich liess ihm Kaunitz sagen, er sei überzeugt, dass die kaiserlichen Majestäten sehr zufrieden mit dieser Wendung der Dinge sein würden. Der kaiserliche Gesandte in München berichtete nämlich, der Kurfürst habe ihn am 14. in der Frühe rufen lassen und nach einer langen Unterredung die Ratificirung des Vertrages versprochen. Ritter nahm die Gelegenheit wahr hervorzuheben, wie die angekündigten Schreiben Karl Theodors an die Majestäten unzweideutige Beweise der Aufrichtigkeit und Standhaftigkeit der Gesinnung seien, und forderte dagegen die Rückkehr des alten Vertrauens von österreichischer Seite, damit das begonnene grosse Werk zu einem erspriesslichen Abschluss geführt werden könne ${ }^{2}$ ).

Endlich um 7 Uhr Abends traf der Courer mit der ratificirten Convention ein. Ritter teilte der Staatskanzlei sogleich den Inhalt des kurfürstlichen Rescripts und der Weisungen Viereggs mit; Tags darauf, am 17., überreichte er den Majestäten die Schreiben seines Herrn und empfieng die Versicherung freundschaftlichster Gesinnung und erneuten vollständigen Vertrauens. Der Kaiser sowohl wie die Kaiserin sprachen überdies den lebhaften Wunsch nach baldigem Abschluss der zweiten Convention aus, damit alsdann nichts mehr die innige Freundschaft der beiden Höfe trüben könne. Wegen des unbegründeten Verdachts, über den sich Karl Theodor in seinem Schreiben beklugte, entschuldigte sich Maria Theresia; sie äusserte zu dem Gesandten: „Wir müssen nun auf das Engste zusammenhalten und inskünftige tür einen Mann stehen." Jetzt vollzog sie auch die Ratification und noch an demselben Tage wurden die Vertragsurkunden ausgetauscht.

Man teilte Ritter num die drei Patente mit, welche inzwischen erlassen worden waren: am 12. Januar hatte Maria Theresia die Einziehung von Mindelheim, am 15. diejenige der böhmischen Lehen in

1) Ritter von Vieregg. Wien. 14. Januar 1778. Orig. Bayr. Geh. St.-A.

2) Ritter an Vieregg. Wien. 16. Januar 1778, Orig. Nr, 14. Bayr. Geh. St.-A. 
der Oberpfalz sowie des ehemals straubingischen Teiles von Niederbayern angeordnet. Colloredo sprach dem Gesandten sein Bedauern aus, dass in Folge der Ratificationsverzögerung an den Grafen Hartig In München bereits ein Manifest abgegangen sei wegen der Besitzergreifung der erledigten Reichslehen, das nicht mehr widerrufen werden könne. Dies war in der That am 14. geschehen; man sandte an diesem Tage an F.M.L. Baron Langlois zwei Packete; das eine sollte er an Hartig abschicken, sobald ihm die Gewährung der Ratification aus München gemeldet werde; traf aber die Nachricht ein, dass die Convention verworfen sei, so ging das andere Packet an Hartig ab. In dem letzeren befanden sich Instruction und Vollmacht für Hartig zur Besitzergreifung des ganzen Herzogtums Bayern und andrer reichslehenbarer Lande, Güter und Gerechtsame, sowıe das gedruckte Manifest, welches diese Massregel den Landesbewohnern ankündigte. Das erste Packet, das abgesendet wurde, enthielt die Instruction für den k. k. Commissär bei der Einziehung der erledigten Reichslehen mit Ausnahme des Herzogtums Bayern, die erforderliche Vollmacht, ferner Bemerkungen über einzelne Lehen und das gedruckte Patent. Obwohl die Aktenstuicke am 14. von Wien abgingen, trugen sie sämmtlich das Datum des 16. Januar 1).

War nun auch die Einziehung der erledigten Reichslehen nicht mehr zu hindern oder rückgängig zu machen, so liess der Kaiser doch dem Kurfürsten auch jetzt wieder die Neuverleihung derselben in Aussicht stellen, wenn sie als eine Belehnung ex nova gratia, also nicht mit Berufung auf den bisherigen bayerischen Besitz, schriftlich erbeten und von der Kaiserin-Königin befürwortet werde.

Das Aufrücken des pfälzischen Hauses in die fünfte Kurwürde beim Erlöschen der bayerischen Linie war bereits durch den Westfälischen Frieden bestimmt worden. Colloredo liess jetzt Karl Theodor auffordern, die dazu nötigen Schritte beim Kaiser zu thun, dagegen wurden noch keine Bestimmungen getroffen über die Führung der herzoglichen Stimmen Bayerns; dies sollte erst geschehen, wenn die Verständigung zwischen beiden Höfen vollständig sei, also vermutlich erst nach Absehluss der zweiten Convention, die ja möglicher Weise das ganze Herzoglum mitsammt der herzoglichen Stimme dem Erzhause überlieferte.

Die Stimmung am Wiener Hof war, seitdem die Annahme der Convention durch Karl Theodor feststand, wie umgewandelt. Ritter berichtet ${ }^{2}$ ), dass die bisher ungünstige Meinung über eine ganze Reihe

1) H. H. u. St.-A. Bavarica 49. Successionssachen 1778.

2) Ritter an Vieregg. Wien. 17. Januar 1778. Orig. Bayr. Geh. St.-A. 
von Personen einer gerechten, ja geradezu optimistischen Beurteilung gewichen sei; man äusserte sich höchst anerkennend über Vieregg; man schenkte Lehrbach wieder das alte Vertrauen; man erklärte, dass Graf Seinsheim stets in hoher Achtung gestanden habe und auch hinfort sich derselben erfreuen werde. Hatte man bisher mit Begünstigung der sächsischen Allodialansprïche gedroht, so versprach man jetzt, sich zu verwenden, dass Sachsen eine mehr entgegenkommende Haltung beobachte, man riet Karl Theodor freundschaftlich in dieser Frage nichts zu übereilen. Es war die Ansicht Maria Theresias und weiter Kreise der österreichischen Hauptstadt, dass nun die bayerische Erbschaftsangelegenheit so gut wie geregelt sei. 